\title{
Stochastic Modeling of California Ground Motions
}

\author{
by Gail M. Atkinson and Walter Silva
}

\begin{abstract}
Ground-motion relations are developed for California using a stochastic simulation method that exploits the equivalence between finite-fault models and a two-corner point-source model of the earthquake spectrum. First, stochastic simulations are generated for finite-fault ruptures, in order to define the average shape and amplitude level of the radiated spectrum at near-source distances as a function of earthquake size. The length and width of the fault plane are defined based on the moment magnitude of the earthquake and modeled with an array of subfaults. The radiation from each subfault is modeled as a Brune point source using the stochastic model approach; the subfault spectrum has a single-corner frequency. An earthquake rupture initiates at a randomly chosen subfault (hypocenter), and propagates in all directions along the fault plane. A subfault is triggered when rupture propagation reaches its center. Simulations are generated for an observation point by summing the subfault time series, appropriately lagged in time. Fourier spectra are computed for records simulated at many azimuths, placed at equidistant observation points around the fault. The mean Fourier spectrum for each magnitude, at a reference nearsource distance, is used to define the shape and amplitude levels of an equivalent point-source spectrum that mimics the salient finite-fault effects. The functional form for the equivalent point-source spectrum contains two corner frequencies.

Stochastic point-source simulations, using the derived two-corner source spectrum, are then performed to predict peak-ground-motion parameters and response spectra for a wide range of magnitudes and distances, for generic California sites. The stochastic ground-motion relations, given in the Appendix for rock and soil sites, are in good agreement with the empirical strong-motion database for California; the average ratio of observed to simulated amplitudes is near unity over all frequencies from 0.2 to $12 \mathrm{~Hz}$. The stochastic relations agree well with empirical regression equations (e.g., Abrahamson and Silva, 1997; Boore et al., 1997; Sadigh et al., 1997) in the magnitude-distance ranges well represented by the data, but are better constrained at large distances, due to the use of attenuation parameters based on regional seismographic data. The stochastic ground-motion relations provide a sound basis for estimation of ground motions for earthquakes of magnitude 4 through 8 , at distances from 1 to $200 \mathrm{~km}$.
\end{abstract}

\section{Introduction}

It has been shown that the use of a Brune point-source spectrum, in conjunction with a stochastic ground-motion model, successfully predicts high-frequency $(f \geq 2 \mathrm{~Hz})$ ground-motion amplitudes for earthquakes in California (Hanks and McGuire, 1981; Boore, 1983) and eastern North America (Atkinson, 1984; Boore and Atkinson, 1987; Toro et al., 1997). The underlying spectrum of ground acceleration for this model has a simple $\omega^{2}$ shape, meaning that the spectral amplitudes decay as $\omega^{-2}$ for frequencies below the corner frequency, where the corner frequency is a function of earthquake size. Despite its success in modeling highfrequency ground motions, the single-corner-frequency point source consistently overpredicts ground motions from moderate-to-large earthquakes at low-to-intermediate frequencies ( $\sim 0.1$ to $2 \mathrm{~Hz}$ ), in California and elsewhere (Boatwright and Choy, 1992; Boore and Atkinson, 1992; Atkinson, 1993; Atkinson and Boore, 1998; Atkinson and Silva, 1997).

Atkinson and Silva (1997) showed that finite-source effects could be the reason for the observed discrepancy between single-corner frequency point-source simulations and empirical data. They compared empirical source spectra for California earthquakes with the predictions of both singlecorner-frequency point-source, and stochastic finite-fault 
simulations. For the finite-fault simulations, the fault was subdivided into a number of subfaults, each of which was modeled as a Brune point source. The spectral shape from the finite-fault modeling matched the observed spectra, as the summation over a number of point sources reproduced the observed spectral sag at intermediate frequencies. By contrast, the single-corner-frequency point-source model could not provide a satisfactory match to the observed spectral shape.

In this article, we postulate that the use of a point-source model, with a two-corner source spectrum, is equivalent to the use of a finite-fault model comprised of Brune subfaults. By equivalent, we mean that the two-corner point-source and finite-fault stochastic models will generate the same median ground motions, when averaged over all azimuths. In this case, stochastic-based ground-motion relations, expressing median expected levels of peak-ground acceleration, velocity, and response spectra as functions of magnitude and distance, can be developed directly from the equivalent pointsource model. This approach has the advantage of simplicity and stability, since the finite-fault model involves more parameters, as well as the requirement to average simulations over many azimuths and slip distributions.

One may question why we would want to develop stochastic-based ground-motion relations for California. To date, this approach to ground-motion relations has been applied primarily to regions where strong-motion data are limited in the magnitude and distance range of engineering interest, such as eastern North America (ENA). In California, by contrast, there are sufficient strong ground motion data to provide a solid foundation for empirical ground-motion relations, at least for earthquakes of moment magnitude (M) 6 to 7 at distances from 10 to $30 \mathrm{~km}$ (e.g., Abrahamson and Silva, 1997; Boore et al., 1997; Sadigh et al., 1997). The development of stochastic-based ground-motion relations for California is nevertheless useful for several reasons. First, the stochastic model provides a conceptual framework for understanding some of the basic underlying physical parameters that control observed ground-motion amplitudes and their variability (e.g., EPRI, 1993; Toro et al., 1997). Second, ground-motion relations that are underpinned by a physical model form a sound basis for ground-motion predictions in magnitude-distance ranges that are not well represented by the empirical database. By contrast, the extrapolation of strictly empirical ground-motion relations is controlled by the selected functional form. The functional form typically has no physical basis, and its extrapolation may even imply conditions that are physically impossible. Thus it is useful to compare the ground-motion relations obtained by the stochastic approach to various empirical relationships to gain insight into the possible errors that may be caused by extrapolation of empirical ground-motion relations. This is a particularly important issue for seismic hazard analysis because the common practice, of necessity, has been to apply selected empirical ground-motion relations over a range of magnitudes and distances that is much wider than that covered by the underlying empirical database.

Finally, the development of a stochastic ground-motion model for California will facilitate comparisons of groundmotion processes between regions. Insights gained from modeling in the data-rich California region can be used to improve ground motion relations for ENA and other regions with few strong-motion data. Model comparisons between California and ENA can be used to address questions of interest. For example: is an earthquake source in ENA equivalent to an earthquake source in California?

In this article, we present stochastic ground-motion relations for California. We compare the stochastic relations to the empirical database and to empirical ground-motion relations. The approach to developing the relations exploits the equivalence between finite-fault models and a two-corner point source. First, stochastic simulations are generated for finite-fault ruptures in order to define the average shape and amplitude level of the radiated spectrum, at near-source distances, as a function of earthquake size. The length and width of the fault plane are defined based on the moment magnitude of the earthquake (Wells and Coppersmith, 1994) and modeled by an array of subfaults. The radiation from each subfault is modeled as a Brune point source using the stochastic model approach (Boore, 1983); the subfault spectrum has a single corner frequency. An earthquake rupture initiates at a randomly chosen subfault (hypocenter) and propagates in all directions along the fault plane, at a specified rupture propagation velocity. A subfault is triggered when rupture propagation reaches its center. Simulations are generated for an observation point by summing the subfault time series, appropriately lagged in time. Fourier spectra are computed for records simulated at many azimuths, placed at equidistant observation points around the fault. The mean Fourier spectrum for each magnitude, at a reference nearsource distance (averaged over all azimuths), is used to define the shape and amplitude levels of an equivalent pointsource spectrum that mimics the salient finite-fault effects. The functional form for the point-source spectrum, involving two corner frequencies, represents the addition of Brune point sources (Atkinson, 1993). The lower corner is related to the size of the finite fault, and the higher corner is related to the subfault size. This reflects the common assumption that large fault ruptures can be modeled by a series of smaller earthquakes (e.g., Hartzell, 1978).

Stochastic point-source simulations are then performed to predict peak-ground-motion parameters and response spectra for a wide range of magnitudes and distances, for generic California rock sites. The source spectrum for the simulations is the equivalent two-corner point-source model established from the finite-fault modeling. The source spectrum is amplified by propagation through the crust, as described by Boore and Joyner (1997), and attenuated by an empirical attenuation function derived from broadband seismographic data (Raoof et al., 1999). For soil sites, the predicted ground-motion amplitudes are modified according to 
the empirical soil factors of Abrahamson and Silva (1997), which express the nonlinear soil amplification as a function of frequency and input rock peak-ground acceleration.

The stochastic ground-motion relations are compared to the empirical database by examining mean residuals and their confidence limits, as a function of magnitude and distance. (The residual is defined as the log of the ratio of the observed ground-motion amplitude to the predicted groundmotion amplitude.) The performance of the two-corner stochastic model, in terms of data residuals, is also compared to that of a Brune point-source model. We show that the two-corner stochastic model has a zero mean residual over all frequencies. The Brune point-source model, with a stress drop of 80 bars, has a zero mean residual for frequencies greater than $1 \mathrm{~Hz}$, but at lower frequencies there are significant negative residuals that grow with magnitude as frequency decreases. The mean residual for the Brune pointsource model at frequencies less than $0.5 \mathrm{~Hz}$ represents a bias of about a factor of two in ground motion predictions; this is a very significant bias from an engineering point of view.

The stochastic ground-motion relations are also compared to the empirical relations developed by Abrahamson and Silva (1997), Boore et al., (1997) and Sadigh et al. (1997). The proposed relations are in good overall agreement with the empirical ground-motion relations within the magnitude-distance ranges that are well represented in the strong-motion database. Finally, we also show that groundmotion predictions from two commonly used stochastic finite-fault methods, those of Silva et al. (1990; Silva and Stark, 1992; Schneider et al., 1993) and Beresnev and Atkinson (1997; 1998a,b; 1999) are approximately equivalent, despite differences in the details of the model formulation.

We conclude that the stochastic finite-fault simulation approach, whether implemented directly, or through the use of an equivalent two-corner point source, is a robust and accurate approach to estimating ground motions. Stochastic relations based on the finite-fault approach are in good agreement (within $+/-20 \%$ at all frequencies) with the empirical California database, for earthquakes of $\mathbf{M} 4.5$ to 7.5 at distances from 0 to $200 \mathrm{~km}$, and are a sound basis for extending ground-motion relations into the magnitude and distance ranges that are not well represented in the empirical database.

\section{Simulation Model}

Stochastic ground-motion relations for California are developed in two steps. First, finite-fault simulations are used to define the shape and amplitude level of the radiated spectrum at near-fault distances, as a function of moment magnitude (M). This equivalent point-source spectrum is then the source spectral model that is input to stochastic point-source simulations. Other input parameters, described in detail later, model the amplification of motions through the California velocity gradient, and the attenuation of ground motion with distance. Point-source simulations are made for earthquakes of magnitude 4.0 through 8.0, at distances from 1 to $200 \mathrm{~km}$ from the fault.

\section{Source Model}

The shape and amplitude levels of the earthquake source spectrum are defined by stochastic finite-fault simulations. The methodology has been described by Schneider et al. (1993) and Beresnev and Atkinson (1997, 1998a). The computations are made with the FINSIM computer code (Beresnev and Atkinson, 1998a), and results are checked against those made with the finite-fault code of Silva (Silva et al., 1990; Silva and Stark, 1992; Schneider et al., 1993).

An earthquake fault is modeled as a vertical plane whose length is determined by the relationship of Wells and Coppersmith (1994) (for earthquakes of all mechanisms):

$$
\log \mathrm{L}=-2.44+0.59 \mathbf{M}
$$

The width of the fault plane is determined from the fault area divided by length, where the length is given above and the area is, from Wells and Coppersmith (1994) (all types):

$$
\log \mathrm{A}=-3.49+0.91 \mathbf{M}
$$

The earthquake fault is discretized as an array of subfaults, each of which is modeled as a stochastic $\omega^{2}$ point source; thus the subsources are Brune point sources. The rupture is assumed to initiate at a random location on the fault, then propagate in all directions with velocity $0.8 \beta$ (where $\beta$ is the shear-wave velocity). Each subsource is triggered as a point source when the rupture reaches its center. The time history at an observation point is obtained by summing the contributions from all subfaults, appropriately lagged in time according to the rupture and propagation time for each of the subfaults. Heterogeneity of the source process is modeled by randomizing the subevent rise times and slip distribution, as described by Beresnev and Atkinson (1998a).

The size of the subfaults controls the spectral shape at intermediate frequencies. From detailed modeling of a range of earthquakes from $\mathbf{M} 4.2$ to 8.5 in a variety of tectonic environments, it was determined that the optimal subfault size is directly related to earthquake magnitude (Beresnev and Atkinson, 1999), and is given by:

$$
\log r=-2.0+0.4 \mathbf{M}
$$

A constant subfault stress drop of 50 bars is assumed. The results have only a weak dependence on subfault stress drop, since this parameter is used only to assign an equivalent subfault moment for the specified subfault size. The number of subfaults to be summed is fixed by the constraint that the total moment must equal the target moment for the total fault dimensions. 
The main "free" parameter of the modeling is the radiation strength factor $s$. The parameter $s$ was introduced by Beresnev and Atkinson (1998a) to measure the strength of high-frequency radiation from faults. It may be related to the maximum slip velocity on the fault, and controls the level of the acceleration spectra above the corner frequency of the subfaults. A value of $s=1.6$ was used in the simulations, in agreement with the value determined from detailed modeling of the Northridge earthquake (Beresnev and Atkinson, 1998b). As we will see later, the value of $s=1.6$ produces a high-frequency level that matches that implied by a Brune (1970) stress drop of 80 bars.

The random horizontal component of ground motion is simulated for ten observation points, uniformly spaced at a specified reference distance from a verically oriented fault plane (e.g., equidistant spacing along a "racetrack" at fixed distance from the fault). Reference distances used range from 1 to $30 \mathrm{~km}$. The Fourier spectrum is defined by averaging the results over all azimuths at the given fault distance, using the logarithmic mean of the amplitudes.

The way the earthquake radiation is represented in the finite-fault model explains why it reproduces the observed "spectral sag" that is missed by the Brune point-source model. The central idea of kinematic modeling involves the discretization of a large fault plane into elements (subfaults), each of which is assigned a corner frequency inversely proportional to its size. The total radiation is then obtained by summing contributions from all subfaults. In the Brune point-source approximation, the corner frequency of a large fault is derived from the full fault dimension, and is thus much lower than that of the subfaults. In the finite-fault approach, each subfault still has a single-corner-frequency spectrum; the "sag" is automatically created by the summation procedure that prescribes the high-frequency level and the total moment (as described by Joyner and Boore, 1986). This summation process is approximated by the functional form used by Atkinson (1993), Atkinson and Boore (1995, 1998), and Atkinson and Silva (1997) to match the empirically derived source spectral shape; their functional form represents the addition of Brune point sources. It is important to recognize that this spectral shape persists at all distances. Thus finite-fault effects, even from a moderate event, can be observed at large distances from the source (Atkinson, 1993; Atkinson and Boore, 1998; Atkinson and Beresnev, 1999).

To define the equivalent point-source spectrum, we perform finite-fault simulations for earthquakes of $\mathbf{M} 4.0$ to 8.0 (in 0.5 unit increments), for random hypocenter locations, at distances from 1 to $30 \mathrm{~km}$ from the fault (at 1, 2, 5, 10, 20, and $30 \mathrm{~km}$ ). In each case, the spectrum is averaged over all azimuths; thus we characterize the average amplitudes as a function of distance. Regression of the average simulated amplitudes versus distance then establishes the average apparent source spectrum, at any chosen reference near-source distance. Since the finite-fault simulations are used just to define the source spectrum, no crustal amplification effects are considered. (These will be applied to the derived source model in the point-source simulations.)

The spectra will attenuate with distance from the fault, due to the combination of geometric attenuation of the subfault radiation ( $\mathrm{R}^{-1}$ amplitude decay) and the effects of the finite-fault geometry. There will also be anelastic attenuation. Anelastic effects are relatively small at near-fault distances, except for very large fault planes. For large faults, anelastic effects over the large distances to the extremities of the rupture plane can cause magnitude-dependent shape changes in the apparent near-source spectrum. These effects may be responsible for the empirical observation that there is an apparent dependence of kappa on magnitude (Durwand et al., 1996; Atkinson and Silva, 1997). In our finite-fault simulations, the included geometric and anelastic attenuation model (from Raoof et al., 1999) is not critical, since whatever attenuation is included is then removed by regression of the simulated spectra to determine the apparent source spectrum. It is just the effects of the finite-fault geometry on the apparent source spectrum that we aim to capture with this regression of simulated spectral amplitudes.

The finite-fault geometry causes the average or effective distance from the observation point to the fault to "saturate" as the fault is approached, since at any point we cannot be close to the entire fault plane. This implies that there is an effective focal depth, which will appear to be the source of the radiation if it is treated as a point. This "equivalent pointsource depth" $(h)$ is a function of fault size, and hence earthquake magnitude. By examining the decay of the average Fourier spectral amplitudes with distance, in the distance range from 1 to $30 \mathrm{~km}$ (from the finite fault simulations), this depth can be represented as

$$
\log h=-0.05+0.15 \mathbf{M}
$$

implying that the effective depth of the radiation increases with magnitude from about $5 \mathrm{~km}$ for $\mathbf{M} 5$ to about $14 \mathrm{~km}$ for $\mathbf{M}$ 8. From the regression of the finite-fault simulation results at fault distances of 1 to $30 \mathrm{~km}$, we define the apparent source spectrum of the radiation, averaged over all azimuths, at the reference distance of $R=1 \mathrm{~km}$, where $R$ $=\sqrt{ }\left(\mathrm{d}^{2}+h^{2}\right)$ with $\mathrm{d}$ being the closest distance to the fault plane. This is the equivalent point-source spectrum. Note that the chosen reference distance of $R=1 \mathrm{~km}$ for the apparent source spectrum is arbitrary, selected for computational convenience; physically, we could never have a point where $R$ is less than $h$.

The equivalent point-source spectrum is characterized by a high-frequency level that corresponds to a Brune pointsource model with a stress drop of 80 bars. However, the spectrum sags at intermediate frequencies, relative to the Brune model, for the reasons discussed earlier. The spectrum can be described by the functional form suggested by Atkinson (1993) and Atkinson and Boore (1998): 


$$
\begin{array}{r}
A_{\mathrm{o}}(f)=\mathrm{C}(2 \pi f)^{2} M_{\mathrm{o}}\left\{(1-\varepsilon) /\left[1+\left(f / f_{\mathrm{a}}\right)^{2}\right]\right. \\
\left.+\varepsilon /\left[1+\left(f / f_{\mathrm{b}}\right)^{2}\right]\right\}
\end{array}
$$

The constant $\mathrm{C}$ is given by $\mathrm{C}=\mathscr{R} \mathrm{V} \mathrm{FS/} /\left(4 \pi R \rho \beta^{3}\right)$, where $\mathscr{R}$ is the radiation pattern ( 0.55 on average for shear waves), $V$ is a partition onto two horizontal components $(1 / \sqrt{ } 2), F S$ is the free surface amplification (2), $R$ is distance from the source, and $\rho$ and $\beta$ are the density and shear-wave velocity, respectively, in the vicinity of the source.

The lower corner frequency, $f_{\mathrm{a}}$, is determined by the source duration $\left(T_{\mathrm{o}}\right)$, where for the 2-corner model we adopt the convention of Boatwright and Choy (1992), that $T_{\mathrm{o}}=$ $1 /\left(2 f_{\mathrm{a}}\right)$. From empirical data on source duration, it follows that (Atkinson, 1993):

$$
\log f_{\mathrm{a}}=2.181-0.496 \mathbf{M} \text {. }
$$

The higher corner frequency, $f_{\mathrm{b}}$, is the frequency at which the spectrum attains $1 / 2$ of the high-frequency amplitude level. By determining $f_{\mathrm{b}}$ for the simulated events of $\mathbf{M} 4.0$ to 8.0 , and fitting these values as a function of $\mathbf{M}$, we obtain:

$$
\log f_{\mathrm{b}}=2.41-0.408 \mathrm{M} \text {. }
$$

The remaining parameter, $\varepsilon$, is a relative weighting parameter whose value lies between 0 and 1 (where for $\varepsilon=1$ the two-corner model is identical to a single-corner Brune model). Its value is determined by fitting the average finitefault spectra defined at $R=1 \mathrm{~km}$ to equation (5). The best fit is obtained for:

$$
\log \varepsilon=0.605-0.255 \mathrm{M} \text {. }
$$

The two-corner functional form provides a satisfactory fit to the amplitude levels, with an average bias of less than $20 \%$ for all events of $\mathbf{M}$ greater than 5. Figure 1 compares the 2corner equivalent-point-source to the Brune spectral model, and to the previous empirically derived California source spectra of Atkinson and Silva (1997). The empirical spectra of Atkinson and Silva (1997) were derived from direct regression analysis of the California ground motion database, and apply to a reference distance of $R=8 \mathrm{~km}$, with an average implied kappa value (near-surface attenuation) of $\kappa$ $=0.04$. In order to allow the comparisons with the empirical results, we have plotted Figure 1 at a reference distance of $R=8 \mathrm{~km}$ (i.e., source spectra defined at $R=1 \mathrm{~km}$ are attenuated to $R=8 \mathrm{~km}$; this is also an arbitrary reference distance). We have also applied the same attenuation factor of $\exp (-\pi \mathrm{f} \kappa)$, with $\kappa=0.04$, to the Brune and 2-corner spectra.

\section{Propagation Model}

The equivalent point-source spectrum, as defined in the previous section, is modified as it propagates through the California crust, by the following processes:

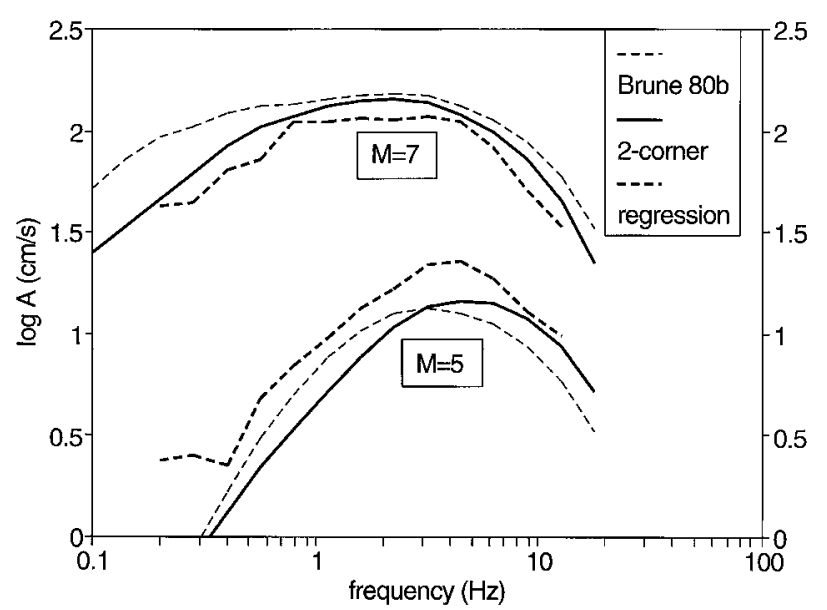

Figure 1. Apparent Fourier acceleration source spectra for California earthquakes of $\mathbf{M} 5$ and 7, at reference distance of $\mathrm{R}=8 \mathrm{~km}$ (including the effects of crustal amplification and kappa). Solid line shows 2-corner model of this study, heavy dotted line shows empirical regression results of Atkinson and Silva (1997), and light dotted line shows Brune single-corner model for a stress drop of 80 bars.

1. Attenuation-The spectrum decays with distance due to geometric spreading and anelastic attenuation. A recent analysis of regional broadband seismographic data from small events (Raoof et al., 1999) determined that the California attenuation can be modeled by geometric spreading of $R^{-1}$ to a distance of $40 \mathrm{~km}$, with $R^{-0.5}$ spreading for $R$ greater than $40 \mathrm{~km}$. The anelastic attenuation associated with this spreading model is represented by a frequency-dependent regional quality factor given by $Q=180 \mathrm{f}^{0.45}$. [Anelastic attenuation is given by $\exp (-\gamma R)$, where $\gamma=\pi f /(Q \beta)$.]

2. Crustal amplification-The spectrum is amplified by the California velocity gradient, as it propagates from the source region, where the shear-wave velocity is $3.5 \mathrm{~km} /$ sec, toward the surface, where the average shear-wave velocity is $620 \mathrm{~m} / \mathrm{sec}$ for generic "rock" sites (Boore and Joyner, 1997). We model this effect by multiplying the spectrum by the frequency-dependent crustal amplification factors of Boore and Joyner (1997) for generic California rock sites; these amplification factors assume linear response for rock sites. Note that use of these factors implies that the ground-motion predictions will apply to an average shear-wave velocity, averaged over the top 30 $\mathrm{m}$, of $620 \mathrm{~m} / \mathrm{sec}$. This is referred to as a "rock" site condition in this article, but might more correctly be called soft rock or stiff soil.

3. Kappa-High-frequency amplitudes are reduced by nearsurface attenuation, through the kappa operator (Anderson and Hough, 1984), by multiplying the spectrum by the factor $\exp (-\pi f \kappa)$. A value of $\kappa=0.03$ is adopted, as a compromise between regional estimates which typically range from about 0.02 to 0.04 (e.g., Anderson and 
Hough, 1984; Boore et al., 1992; Atkinson and Silva, 1997; Boore and Joyner, 1997).

4. Soil response-For rock sites, the spectrum is completely described by the source spectrum as modified by the earlier three processes. For soil sites, we must also consider site amplification through the soil column, including the effects of soil nonlinearity for strong ground shaking. In this article, we treat this problem empirically, by adopting the soil response factors determined by Abrahamson and Silva (1997) from the strong-motion database. These factors give the frequency-dependent site response factors for response spectra, as a function of the expected peak ground acceleration (PGA) amplitude on rock. Therefore we need only model the ground motions for rock sites (including the expected rock PGA) and can simply adjust the predicted response spectra for soil sites using the empirical factors. An alternative approach would be to treat the soil response analytically, by propagating the rock motions through a specified soil column, using an equivalent linear soil response methodology. Such an approach is most useful in site-specific analyses (e.g., Silva et al., 1990), and has also been proposed for defining generic amplification functions in California (Ni et al., 1999).

The net effect of the amplification processes described above is illustrated in Figure 2 for rock sites (linear), and for soil sites at weak (linear) and strong (nonlinear) levels of shaking.

Other physical characteristics that are input to the stochastic point-source simulations include the regional physical constants $\rho$ (crustal density) and $\beta$ (shear-wave velocity in the source region). These are taken as $\rho=2.8 \mathrm{gm} / \mathrm{cm}^{3}$ and $\beta=3.5 \mathrm{~km} / \mathrm{sec}$ (Boore and Joyner, 1997). The duration of motion has been shown to increase in a complex and apparently frequency-dependent manner with distance, due to the effects of scattering and dispersion (Raoof et al., 1999). We adopt a simplified representation of this distancedependent duration as:

$$
T=T_{\mathrm{o}}+0.05 R
$$

where $T_{\mathrm{o}}$ is the source duration, given by $T_{\mathrm{o}}=1 /\left(2 f_{\mathrm{a}}\right)$ (Boatwright and Choy, 1992).

\section{Point-Source Simulation Model}

Stochastic point-source simulations are performed for the specified source and propagation model, using the wellknown stochastic point-source method (Boore, 1983; Atkinson and Boore, 1995; Boore, 1996; Toro et al., 1997). The method begins with the generation of a windowed time series of bandlimited random white Gausian noise with zero mean amplitude; the variance is chosen such that the geometric mean of the spectral amplitude is unity. Normalization based on the geometric mean (i.e., averaging of the $\log$ amplitudes) of the spectrum is chosen for consistency with the definition of the source spectral model, which was fitted

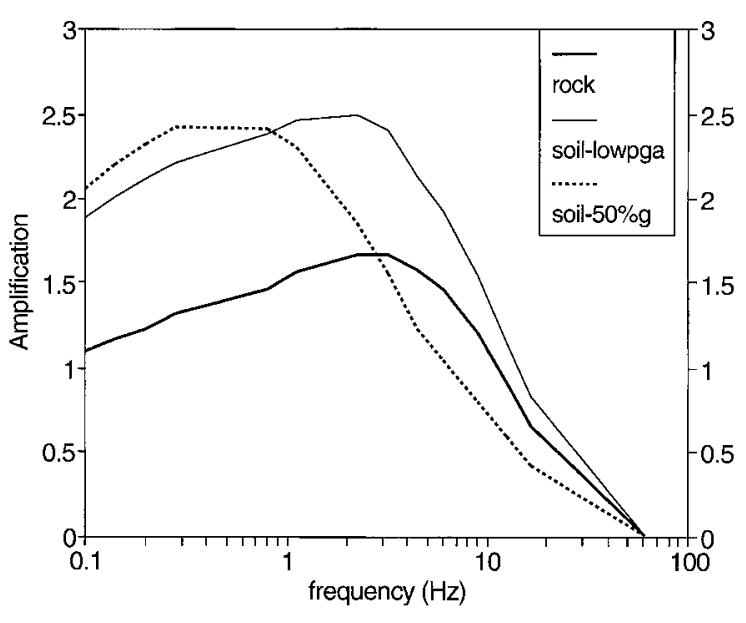

Figure 2. Total amplification effects for generic California crust, including amplification through velocity gradient and kappa for rock sites (dark solid line). Dotted lines also include soil amplification for generic soil sites at weak (light solid line) and strong (dotted line) levels of input rock motion.

to mean log amplitudes; furthermore, we also evaluate the residuals in terms of log amplitudes. The spectrum of the windowed time series is multiplied by the desired Fourier amplitude spectrum and transformed back to the time domain to yield a final time series. By repeating the process many times, changing just the seed of the pseudo-random number generator, a suite of representative time series is obtained, from which response spectra can be calculated. The total radiation - the Fourier spectrum by which the unitamplitude noise spectrum is multiplied—is given by (Boore, 1983):

$$
A(f)=A_{\mathrm{o}}(f) V(f) G(f) \exp (-\gamma(f) R) \exp (-\pi f \kappa)
$$

$A_{o}$ is the source spectrum as defined in equation (5). V(f) describes the amplification of the spectrum through the crustal velocity gradient, as given by Boore and Joyner (1997) for generic California rock sites. $G(f)$ is the geometric spreading factor, which is $\mathrm{R}^{-1}$ for $\mathrm{R} \leq 40 \mathrm{~km}$, and $\mathrm{R}^{-0.5}$ for $R>40 \mathrm{~km}$, while $\gamma(\mathrm{f})$ is the anelastic attenuation, as determined from the regional quality factor $Q=180 f^{0.45}$ (all attenuation constants from Raoof et al., 1999). The nearsurface attenuation (Anderson and Hough, 1984) is given by $\kappa=0.03$. Note that since simulations are made for rock sites only, no soil amplification is included. Soil sites are considered by applying empirical soil factors to the derived rock relations.

Simulations are performed for magnitudes from 4.0 to 8.0, in magnitude increments of 0.2 units, and for fault distances from 1 to $200 \mathrm{~km}$ (at 1, 2, 3, 5, 10, 20, 30, 40, 50, 100,150 , and $200 \mathrm{~km}$ ). Average response spectra (logarithmic mean) are computed over 10 trials for each magnitudedistance combination. 


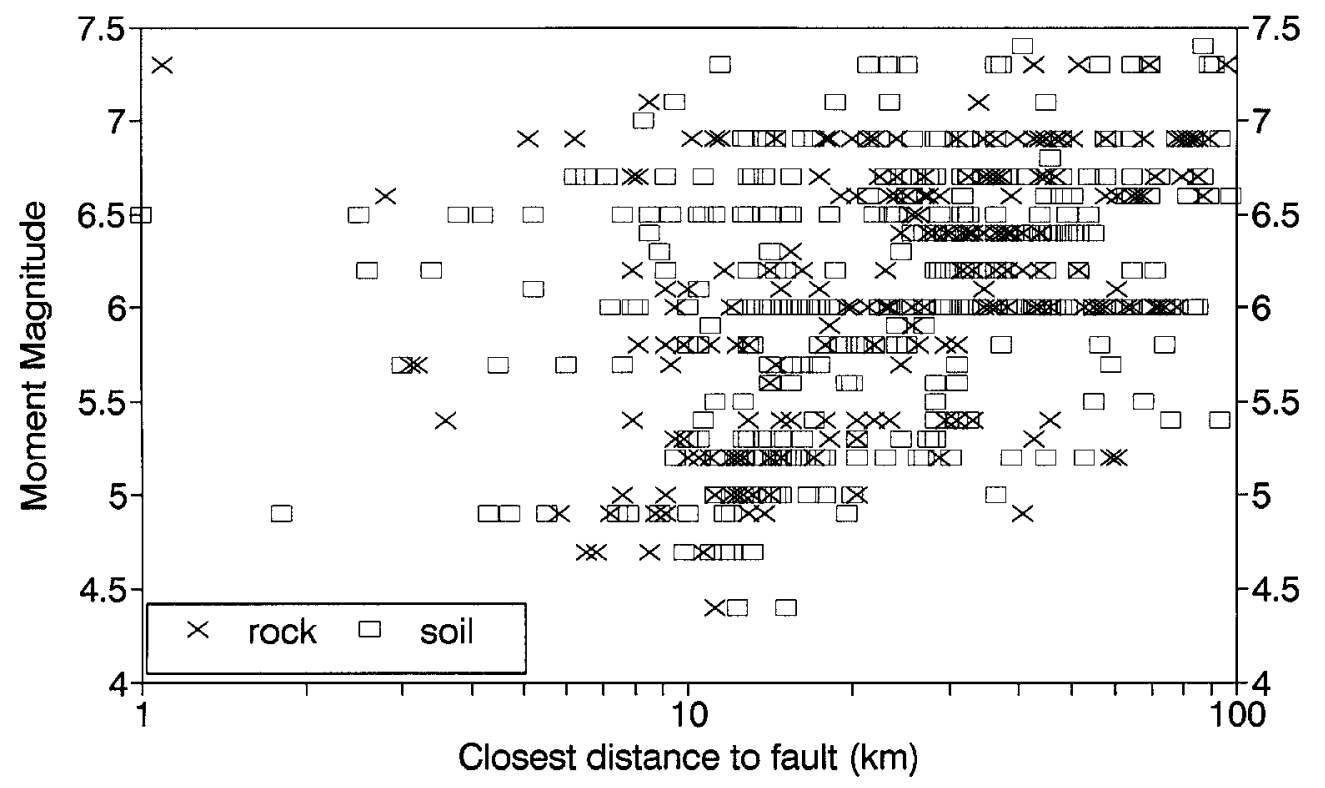

Figure 3. Distribution of empirical California strong-motion database in magnitude and distance.

\section{Results and Discussion}

The median response spectra and peak ground motions for rock site conditions $(\beta=620 \mathrm{~m} / \mathrm{sec})$, from the stochastic equivalent-point-source simulations, are listed in the Appendix. (An electronic version of this table is available to all interested parties; send an e-mail request to gma@ccs .carleton.ca.) For soil sites, motions are obtained by multiplying the response spectra for rock sites by the empirical factor S(f, PGA) of Abrahamson and Silva (1997), given by:

$$
\ln \mathrm{S}(f, \mathrm{PGA})=a_{10}+a_{11} \ln \left(\overline{\mathrm{PGA}}_{\mathrm{rock}}+c_{5}\right)
$$

where $\overline{\mathrm{PGA}}_{\text {rock }}$ is the expected PGA on rock (given in the Appendix table), and $a_{10}, a_{11}$, and $c_{5}$ are frequency-dependent regression coefficients determined by Abrahamson and Silva (1997); for convenience, these coefficients are reproduced in the Appendix.

\section{Comparison of Ground Motion Relations}

to California Database

The ground-motion predictions can be compared to the empirical database for California. The database for the comparisons is the California strong-motion catalog of Pacific Engineering and Analysis, as described by Atkinson and Silva (1997). In total there are 536 rock records (Geomatrix site categories $\mathrm{A}$ and $\mathrm{B}$, corresponding to rock and stiff, shallow soil) and 931 soil records (Geomatrix site categories $\mathrm{C}$ and $\mathrm{D}$, corresponding to deep soil), with a magnitudedistance distribution as plotted in Figure 3 . The fit of the predictions to data is assessed by examining the residuals, where the residual is defined as the log (base 10) of the ratio of the observed ground-motion amplitude to the predicted ground-motion amplitude. Thus data amplitudes that exceed the predictions are plotted as positive residuals.

We first show that the rock and soil predictions produce an equivalent fit to the data, in order to justify combining site categories in subsequent comparisons. Figure 4 plots the $90 \%$ confidence limits of the mean residual, averaged over all events of $\mathbf{M} \geq 6.5$ at $\mathrm{d} \leq 50 \mathrm{~km}$, for rock and soil sites. The mean residual (which lies halfway between the $+90 \%$ and $-90 \%$ confidence limits) is close to zero, for both rock or soil sites, for all frequencies from $0.25 \mathrm{~Hz}$ to $10 \mathrm{~Hz}$. This indicates that the relations are in good overall agreement with the observed ground motions from large events, and that the empirical soil factors are doing a good job of pro-

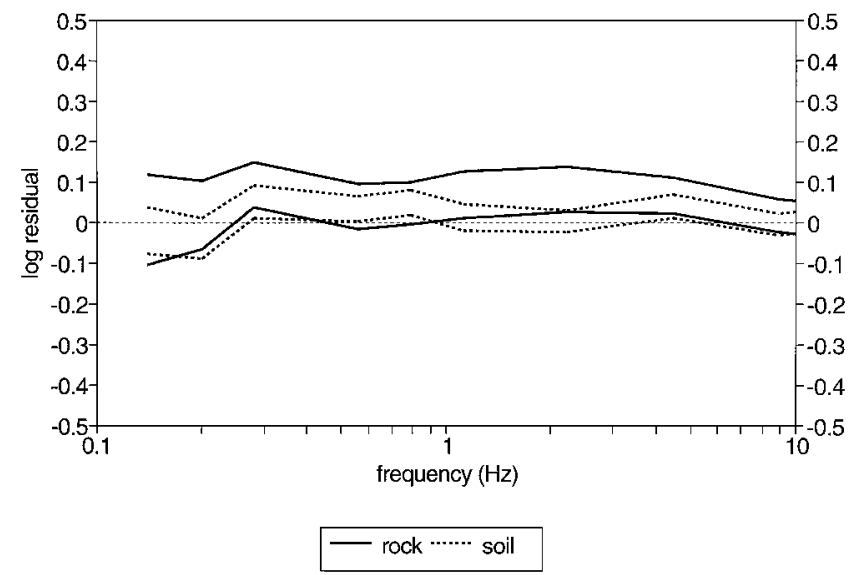

Figure 4. $90 \%$ confidence limits on the mean residual for the 2-corner equivalent point-source model, for rock (solid) and soil (dotted) data, for all earthquakes of $\mathbf{M} \geqq 6.5$ within $50 \mathrm{~km}$ of the fault. 
ducing equivalence between soil and rock predictions. This equivalence between the rock and soil residuals is not sensitive to choice of magnitude or distance range examined. When averaged over all magnitudes and distances in the strong-motion database, the residuals are near zero at all frequencies; the maximum mean residual at any frequency represents an error of less than $20 \%$ on predicted ground motion amplitudes.

To gain a qualitative appreciation for the distribution of the residuals, we plot a sample of the individual residuals as function of distance, for two frequencies, for events of $\mathbf{M} \geq$ 6 , on Figure 5. On Figure 6, we show how the residuals vary with magnitude, for distances within $50 \mathrm{~km}$ of the fault. It is apparent that the scatter of data about the relations is large (average residual of about $0.3 \mathrm{log}$ units, or a factor of two in amplitude), making the degree of fit difficult to judge. The data appear to be well represented by the ground-motion relations, on average, with some notable exceptions.

We next analyze the residuals more quantitatively, in order to explore the adequacy of the stochastic relations in various magnitude and distance ranges. For these comparisons, we have combined the rock and soil residuals in order to use the largest number of data points possible in each magnitude-distance range. (This is justified by the previous figures.) We plot the $90 \%$ confidence limits of the mean residual for the response spectra ground-motion predictions, for a given magnitude-distance range, as a function of frequency.

For comparison, we also show the corresponding residuals for the Brune single-corner-frequency source model. To compute the Brune-model ground-motion predictions, we repeat the simulations, using a Brune (1970, 1971) point

(a) $0.5 \mathrm{~Hz}$

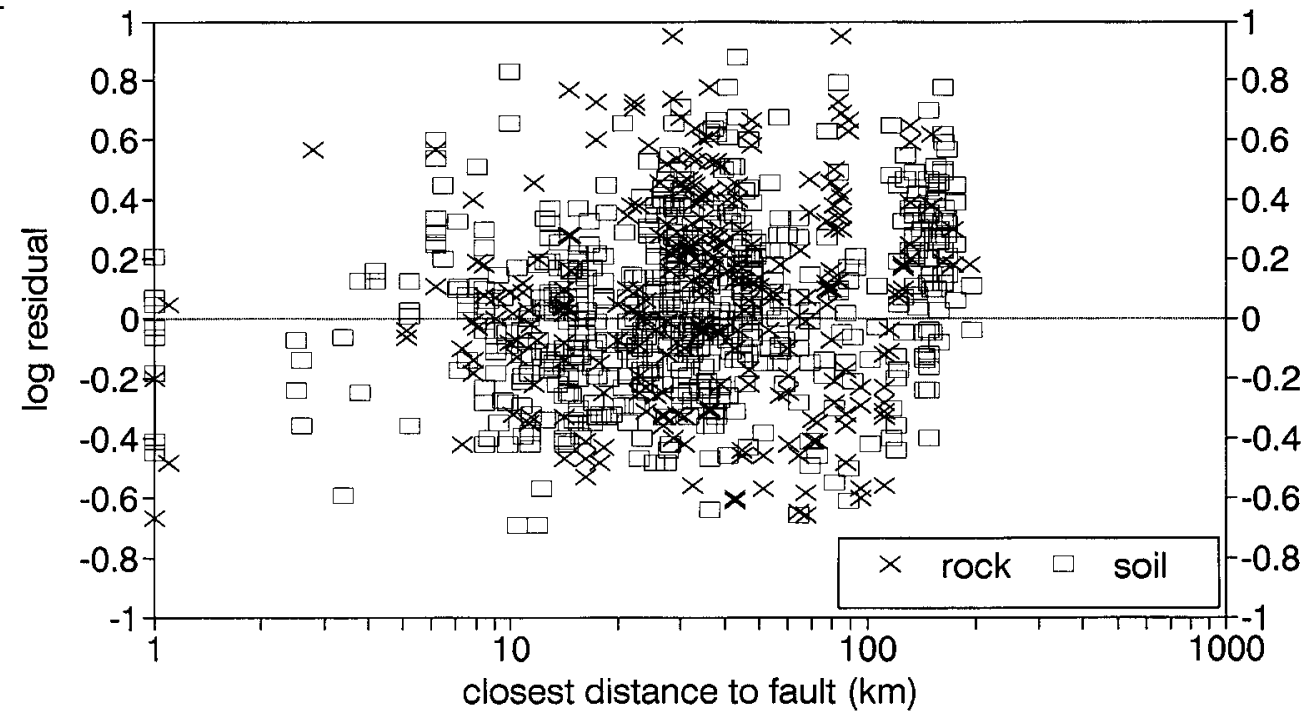

(b) $5 \mathrm{~Hz}$

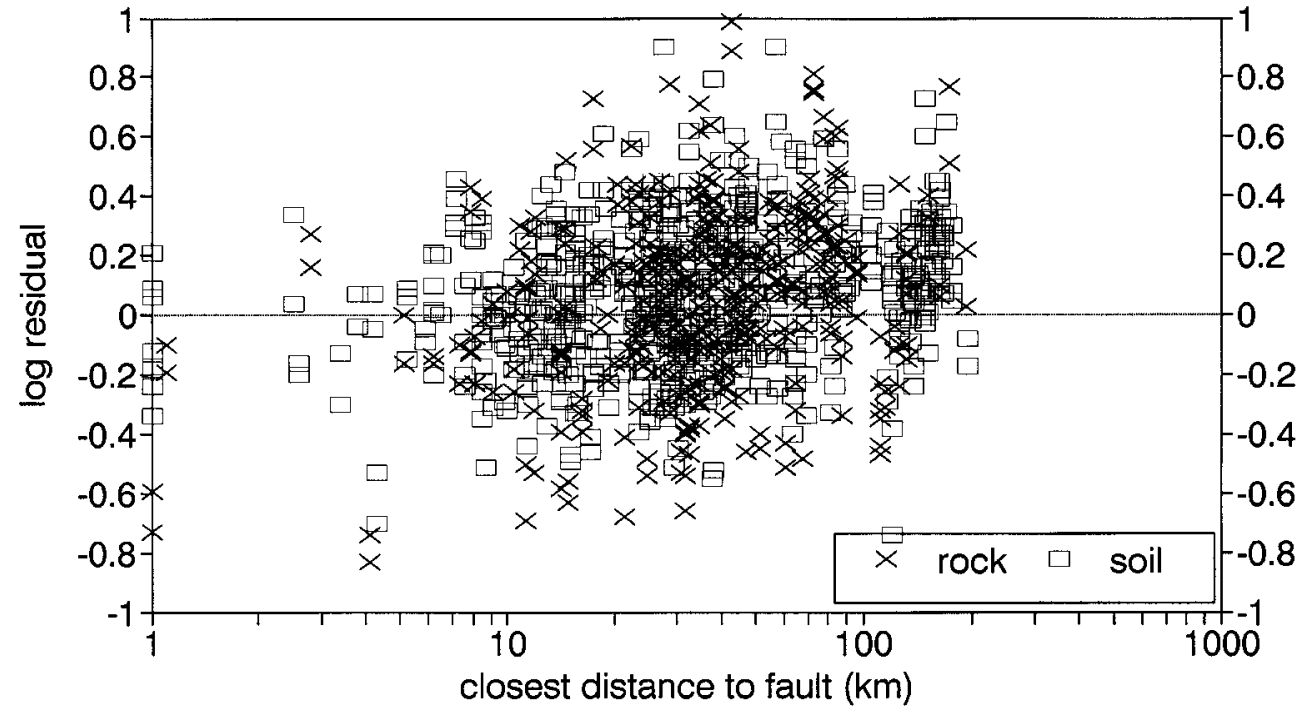

Figure 5. Distribution of residuals with distance, for all events of $\mathbf{M} \geqq 6$, for the 2-corner equivalent point-source model, for frequencies of (a) $0.5 \mathrm{~Hz}$ and (b) $5 \mathrm{~Hz}$. 
(a) $0.5 \mathrm{~Hz}$

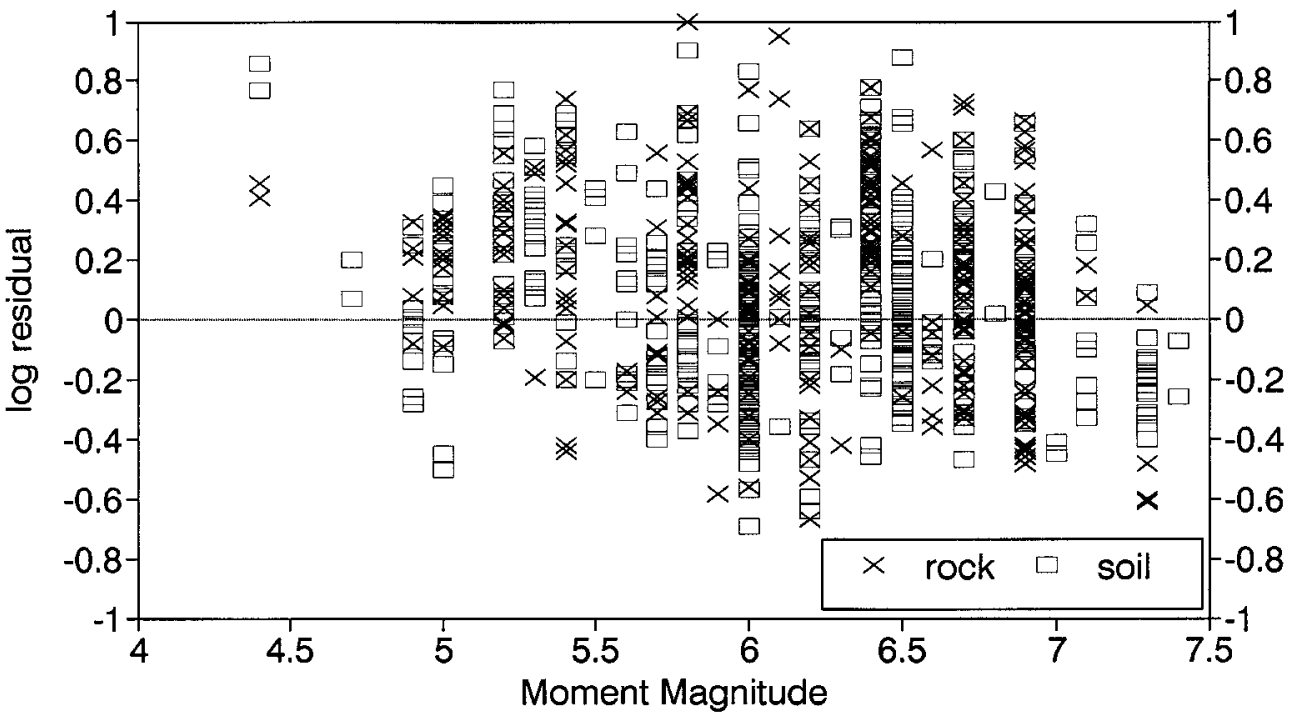

(b) $5 \mathrm{~Hz}$

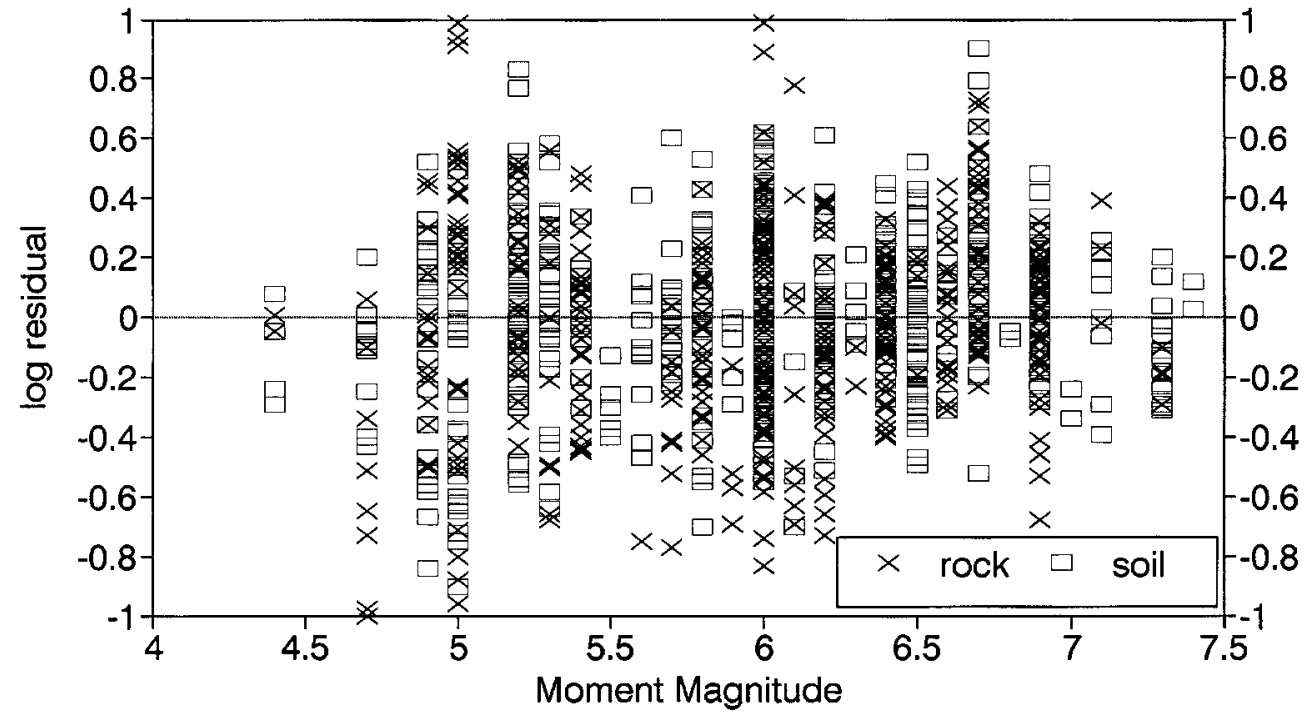

Figure 6. Distribution of residuals with magnitude, for all recordings within $50 \mathrm{~km}$ of the fault, for the 2-corner equivalent point-source model, for frequencies of (a) 0.5 $\mathrm{Hz}$ and (b) $5 \mathrm{~Hz}$.

source to define $A_{o}(f)$ in equation (10). Thus we define the Brune source model using:

$$
\mathrm{A}_{\mathrm{o}}(f)=\mathrm{C}(2 \pi f)^{2} \mathrm{M}_{\mathrm{o}} /\left[1+\left(f / f_{\mathrm{o}}\right)^{2}\right]
$$

where $f_{o}=4.9 \times 10^{6} \beta\left(\Delta \sigma / M_{o}\right)^{1 / 3}$ for constant-stress scaling (Boore and Atkinson, 1987), with $\Delta \sigma=80$ bars and $\beta=3.5 \mathrm{~km} / \mathrm{sec}$. The source duration that is typically assumed for the Brune model is $\mathrm{T}_{\mathrm{o}}=1 / \mathrm{f}_{\mathrm{o}}$ (e.g., Hanks and McGuire, 1981; Boore, 1983; Boore and Atkinson, 1987; Toro et al., 1997). All other parameters remain the same as for the 2-corner source-model simulations.

Figure 7 plots the mean residuals for the 2-corner and Brune source models for small-to-moderate earthquakes (M 4.5 to 6 ) in three distance ranges: $1-10 \mathrm{~km}, 10-20 \mathrm{~km}$, and
20-50 km. For this magnitude range, the goodness-of-fit of the 2-corner and Brune models to the data is approximately equivalent. The differences between the source models are not large for magnitudes less than 6 , because the sag in the 2 -corner model is only pronounced at large magnitudes and low frequencies, for which the finite-fault effects become significant. At small magnitudes $(\mathbf{M} \leq 5)$, the Brune and finite-fault models are practically equivalent. The models predict approximately the same ground motions at high frequencies $(f \geq 2 \mathrm{~Hz}$ ), controlled by the 80-bar stress drop (equivalent to $s=1.6$ ). For both models, the mean residuals in this frequency range are near zero, except at distances less than $10 \mathrm{~km}$ from the fault, for which both models tend to overpredict the ground motions by about 50\% (0.2 log units). It is possible that this overprediction is due to nonlinear ef- 
(a) $1-10 \mathrm{~km}$

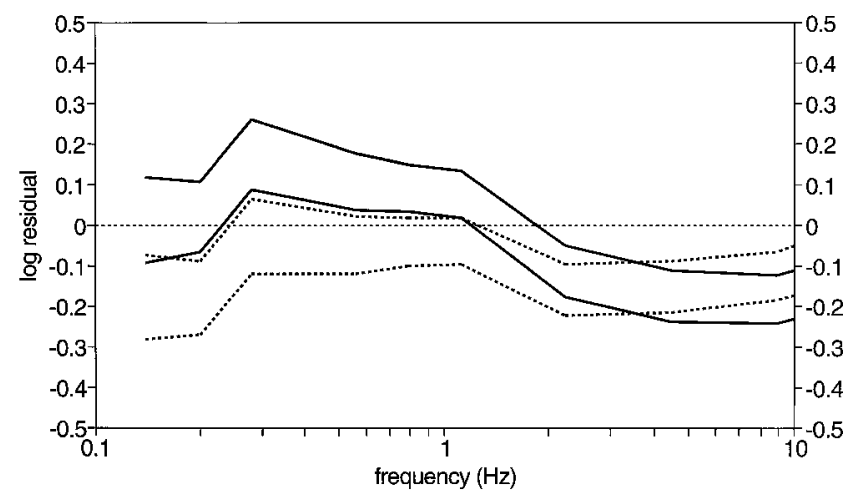

(b) $10-20 \mathrm{~km}$
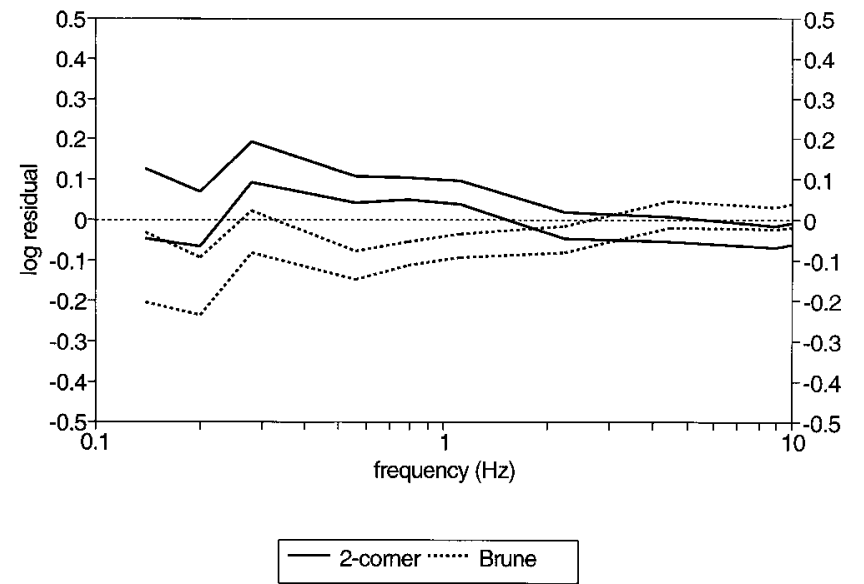

(c) $20-50 \mathrm{~km}$

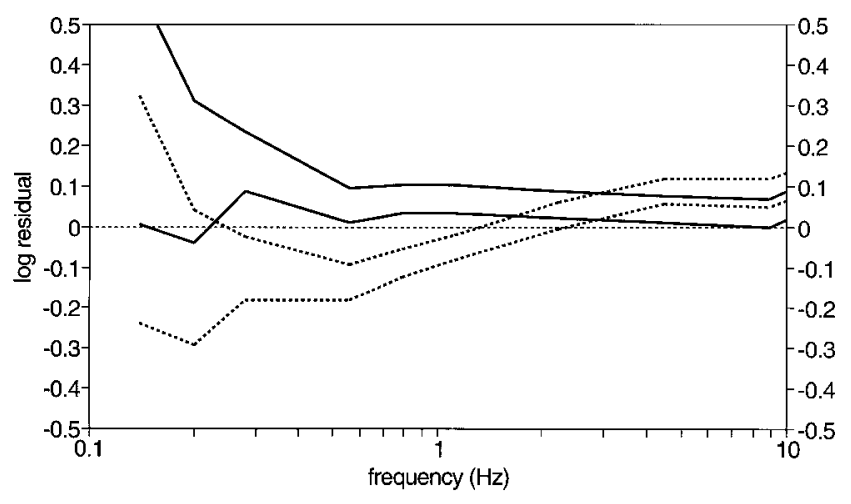

- 2-comer ….... Brune

Figure 7. $90 \%$ confidence limits on the mean residual for earthquakes of $\mathbf{M} 4.5$ to 6.0 , including both rock and soil data, for distance ranges of (a) 1-10 km, (b) 10-20 $\mathrm{km}$, and (c) 20-50 km. Residuals for the 2-corner equivalent point-source model (solid lines) are compared to those for the Brune 80-bar model (dotted lines).

fects that are stronger than those assumed in the modeling. At lower frequencies $(\leq 1 \mathrm{~Hz})$, the 2-corner model underpredicts ground motions from the $\mathbf{M} 4.5$ to 6 data by about $20 \%$, while the Brune model overpredicts by a similar amount. (This reflects the differences in amplitudes between the source models in this magnitude range, as seen in Figure 1.)

Figure 8 plots the mean residuals for moderate-to-large earthquakes (M 6 to 7.4) in four distance ranges: $1-10 \mathrm{~km}$, $10-20 \mathrm{~km}, 20-50 \mathrm{~km}$, and $50-150 \mathrm{~km}$. In this magnitude range, the 2-corner model is in good overall agreement with the data, with the maximum mean residual being less than $0.1 \log$ units (about 20\%) in nearly all cases. The Brune model, by contrast, clearly overpredicts the data at low-tointermediate frequencies $(\leq 1 \mathrm{~Hz})$ at all distances, often by as much as $0.3 \log$ units (a factor of 2). Again, the models are equivalent at high frequencies $(\geq 2 \mathrm{~Hz})$.

The residuals show that the 2-corner stochastic model is a slightly conservative fit to the data for moderate-to-large earthquakes, except for distances greater than $50 \mathrm{~km}$ at $f>$ $2 \mathrm{~Hz}$, for which there is a tendency toward underprediction. This suggests that the anelastic attenuation prescribed by the adopted regional Q model of Raoof et al. (1999) may be too strong. On the other hand, regional attenuation is better determined from the seismographic data analyzed by Raoof $e t$ $a l$. than from strong-motion data, which tend to suffer from bias problems due to nontriggered instruments. Thus the apparent underprediction of high-frequency amplitudes at large distances may be an artifact of biased data sampling.

In Figure 9, we compare the stochastic ground-motion relations to the empirical ground-motion relations of Abrahamson and Silva (1997), Boore et al. (1997), and Sadigh et al. (1997), for an event of M 6.5, at frequencies of 0.25, 1, and $5 \mathrm{~Hz}$. (Note: the Boore et al. relations are not defined for $\mathrm{f}=0.25 \mathrm{~Hz}$, and are therefore shown only for $\mathrm{f}=1 \mathrm{~Hz}$ and $\mathrm{f}=5 \mathrm{~Hz}$.) All of the empirical relations were derived by regression analysis of the California strong-motion database. Figure 9 also compares the simulations of this study 
(a) $1-10 \mathrm{~km}$

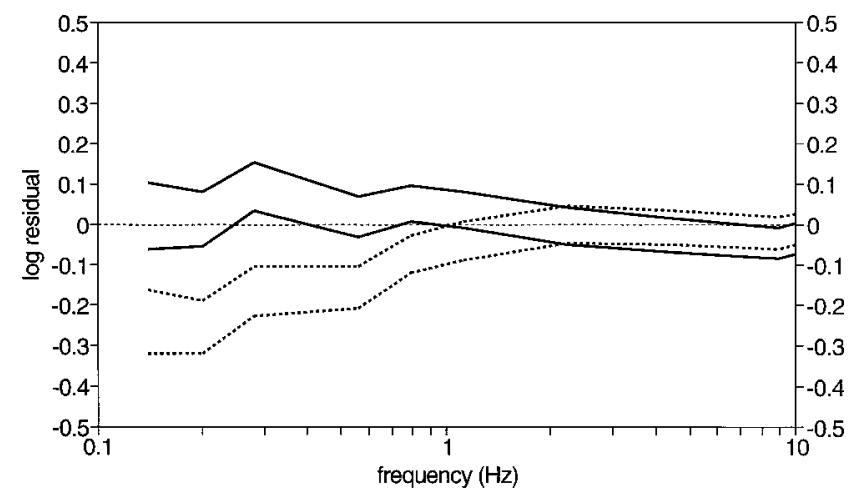

(c) $20-50 \mathrm{~km}$

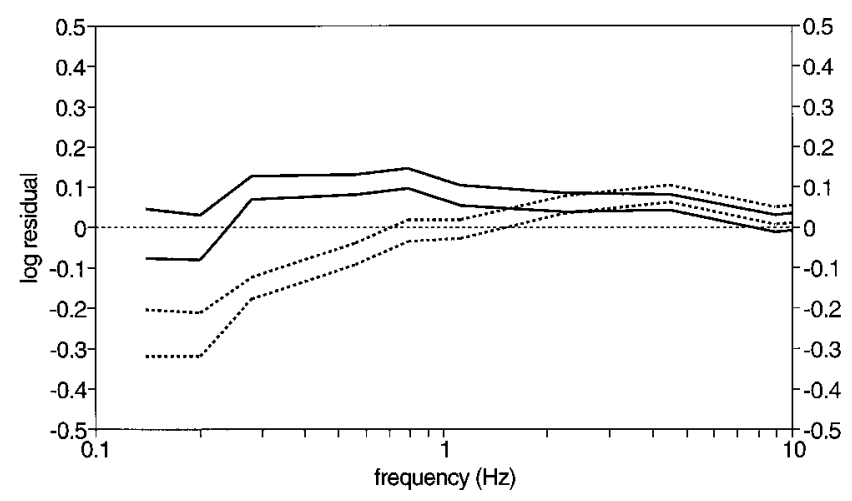

- 2-comer ….... Brune (b) $10-20 \mathrm{~km}$

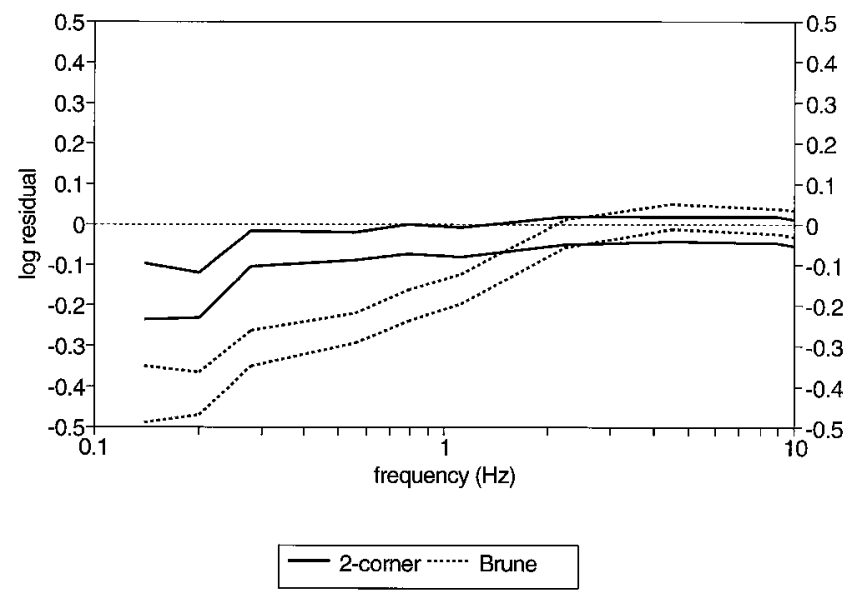

(d) $50-150 \mathrm{~km}$

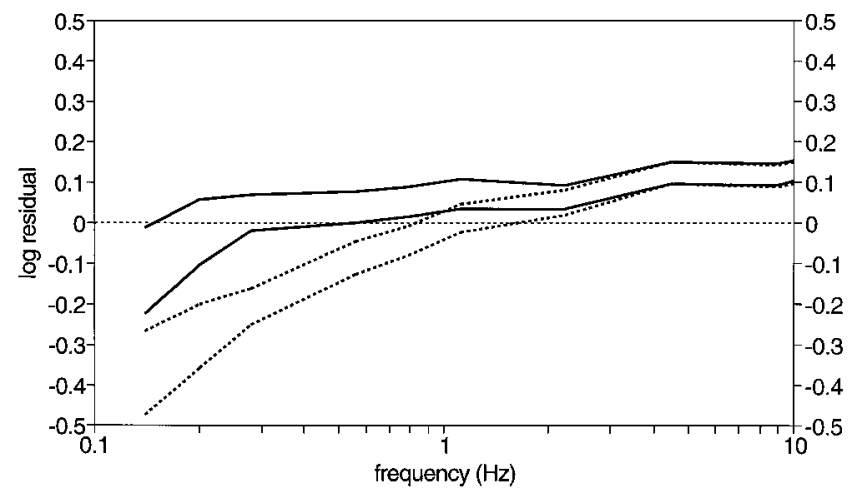

- 2-corner -....... Brune

Figure 8. $90 \%$ confidence limits on the mean residual for earthquakes of $\mathbf{M} 6.0$ to 7.5 , including both rock and soil data, for distance ranges of (a) 1-10 km, (b) 10-20 $\mathrm{km}$, (c) $20-50 \mathrm{~km}$, and (d) $50-150 \mathrm{~km}$. Residuals for the 2-corner equivalent pointsource model (solid lines) are compared to those for the Brune 80-bar model (dotted lines).

to two alternative simulations; these are the ground-motion relations for the Brune (single-corner-frequency) 80-bar source model (as described earlier), and the stochastic finitefault simulations made using the alternative methodology of Silva et al. (1990). The stochastic simulations of Silva et al. are very similar in concept to those presented here, but were generated using somewhat different assumptions regarding fault dimensions, subfault size, rise time, and attenuation, as described by Schneider et al. (1993). The Silva et al. simulations have been validated in more detail against specific individual earthquakes in this magnitude range, including the Loma Prieta, Landers, Whittier Narrows, and Northridge events (Schneider et al., 1993; Abrahamson et al., 1990).

At magnitude 6.5, the relations all agree well with each other in the distance range that is well-constrained by data, namely from about 10 to $60 \mathrm{~km}$ (see Figure 3). There is a notable exception: the Brune model predictions exceed the empirical relations and the other simulation results by a significant amount at low frequencies $(0.25 \mathrm{~Hz})$. At large distances, the empirical relations tend to diverge significantly from each other, reflecting the extrapolation of differing functional forms beyond the distance range of the data. At near distances, the relations are generally in good agreement with each other, although the Boore et al. (1997) empirical relations feature significantly lower amplitudes at high frequencies than do the other relations.

Figure 10 provides further comparisons between the stochastic simulation relations of this study and the empirical relations, over a larger magnitude range. Overall, the agreement between the stochastic-based and empirical relations is surprisingly good, considering the very different methods and assumptions used in their derivation. Since the attenuation in the simulations is controlled by regional seismographic data, obtained at distances from near-source to hun- 
(a) $0.25 \mathrm{~Hz}$

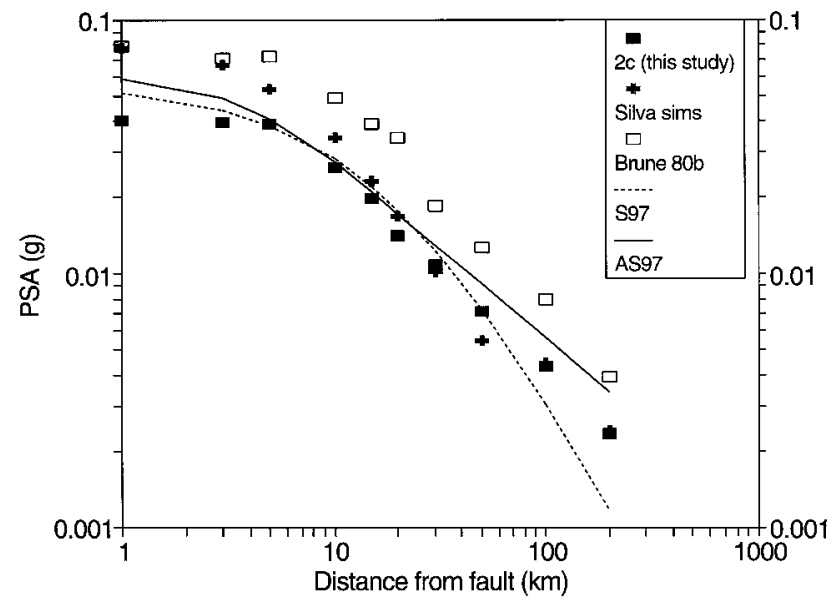

(b) $1 \mathrm{~Hz}$

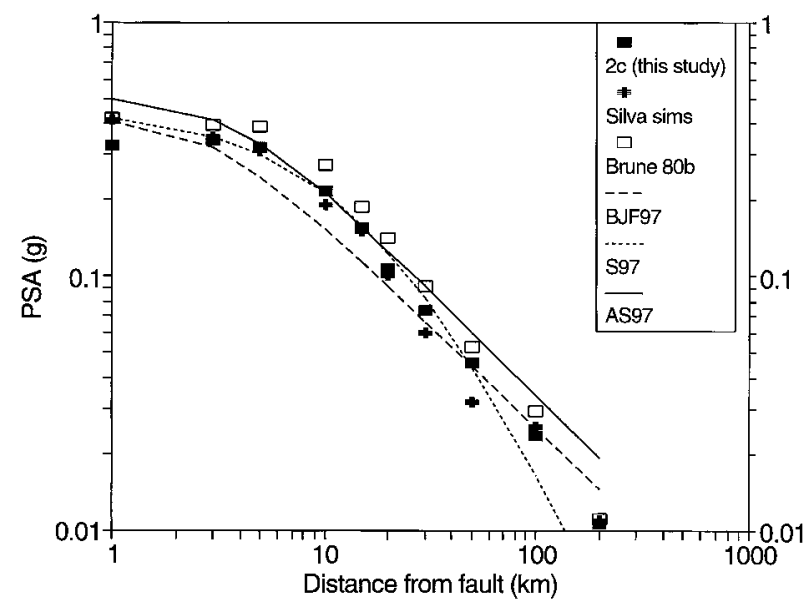

(c) $5 \mathrm{~Hz}$

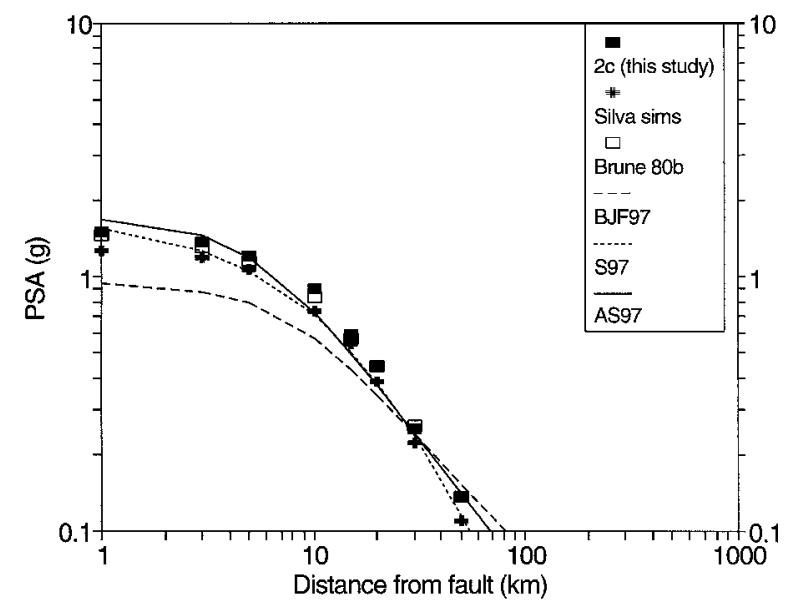

Figure 9. Comparison of 2-corner simulation results of this study (solid squares) with the empirical ground motion relations of Abrahamson and Silva, 1997 (solid lines), Boore et al., 1997 (dashed lines) and Sadigh et al., 1997 (dotted lines), for earthquakes of M 6.5. Simulation results for the alternative finite-fault formulation of Silva et al (plus symbols), and for a Brune 80-bar point source (open squares), are also shown. Comparisons are plotted for PSA at frequencies of (a) $0.25 \mathrm{~Hz}$, (b) $1 \mathrm{~Hz}$, and (c) $5 \mathrm{~Hz}$.

dreds of km (Raoof et al., 1999), it should be more reliable at large distances than are the empirical relations derived from just the strong-motion database.

\section{Standard Deviation of Residuals}

We have shown that the stochastic ground motion relations provide a near-zero mean residual, when evaluated against the California ground motion database. The standard deviation of residuals $(\sigma)$, expressing the variability of observations about the mean, is an important parameter for seismic hazard analysis. (The expected value of the groundmotion parameter for any specified probability level increases with increasing ground-motion variability.) Examination of the standard deviation of residuals shows that this parameter is frequency dependent, and that at high frequencies it is also magnitude dependent; we find no significant dependence on distance. Furthermore, the variability appears to be somewhat larger for rock sites than for soil sites. These results are summarized in Table 1, which gives the standard deviation of residuals for small versus large magnitudes (M $<6$ and $\mathbf{M}>6$, respectively, combining both rock and soil residuals), and for rock versus soil data. The latter values are most appropriate for hazard analysis, as they were computed for the magnitude-distance range of most interest: $\mathbf{M}$ $\geq 6.5$, at distances less than $50 \mathrm{~km}$. The greater variability for "rock" sites probably reflects the variability of site conditions included in this category. The reduction in variability for large magnitudes may be due to the effects of soil nonlinearity.

These levels of variability, and their general dependence on frequency and magnitude, are comparable to those obtained by strictly empirical ground-motion relations, such as 
(a) $0.25 \mathrm{~Hz}$

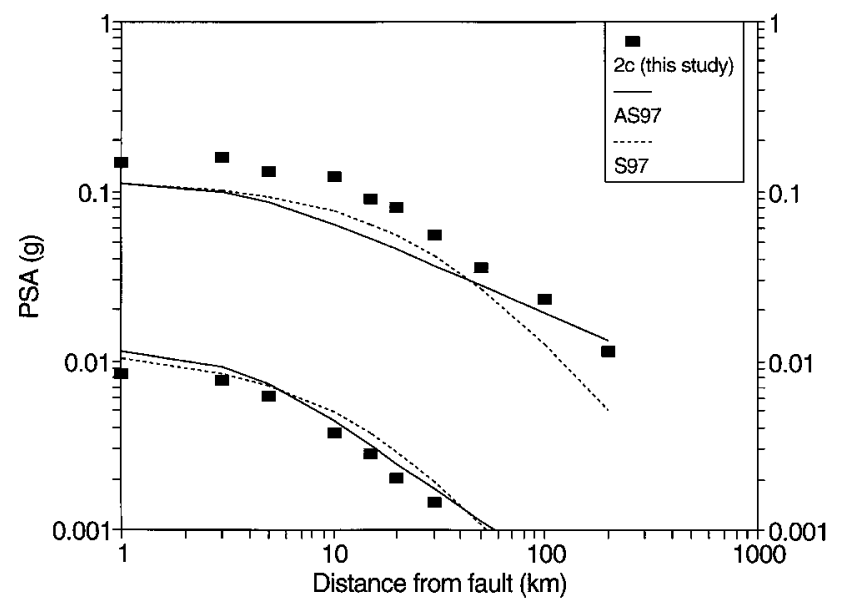

(b) $1 \mathrm{~Hz}$

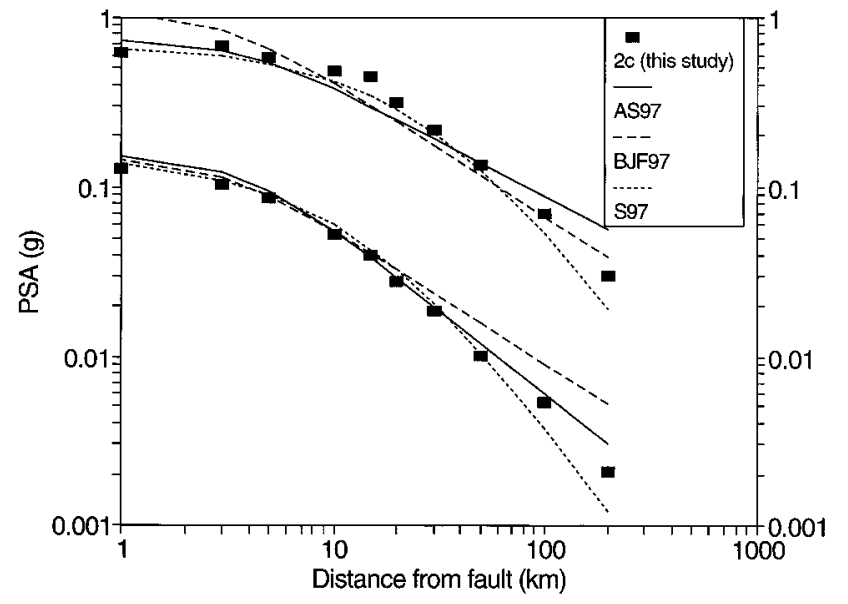

(c) $5 \mathrm{~Hz}$

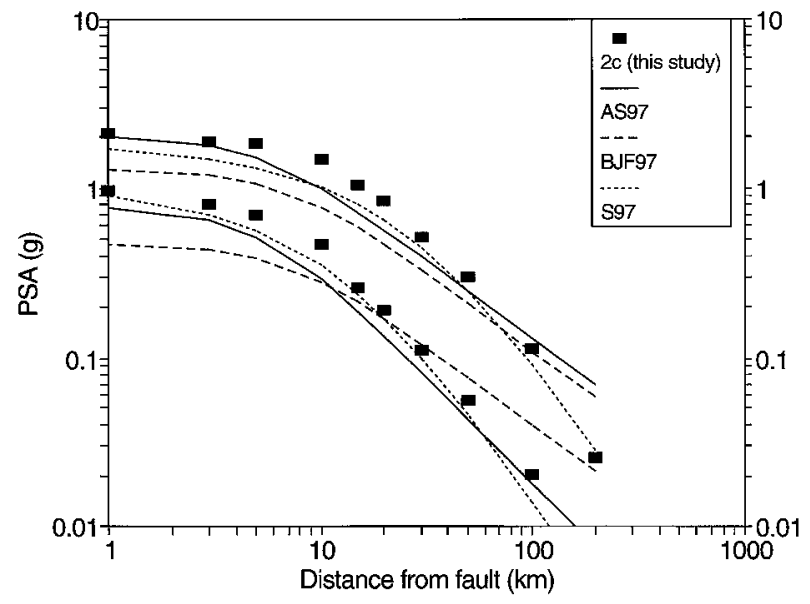

Figure 10. Comparison of 2-corner simulation results of this study (solid squares) with the empirical ground motion relations of Abrahamson and Silva, 1997 (solid lines), Boore et al., 1997 (dashed lines) and Sadigh et al., 1997 (dotted lines), for earthquakes of M 5.5 and 7.5. Comparisons are plotted for PSA at frequencies of (a) $0.25 \mathrm{~Hz}$, (b) $1 \mathrm{~Hz}$, and (c) $5 \mathrm{~Hz}$.

Table 1

Standard Deviation of the Residuals for the Stochastic Ground Motion Relations*

\begin{tabular}{ccccccc}
\hline & \multicolumn{2}{c}{ rock and soil data combined } & & \multicolumn{2}{c}{$\mathbf{M} \geq 6.5, \mathrm{~d} \leq 50 \mathrm{~km}$} \\
\cline { 2 - 3 } \cline { 5 - 6 } Frequency & $\sigma$ for $\mathbf{M} 4.5-6.0$ & $\sigma$ for $\mathbf{M} 6.0-7.5$ & & $\sigma$ for rock & $\sigma$ for soil \\
\hline 0.14 & 0.36 & 0.37 & & 0.43 & 0.37 \\
0.20 & 0.34 & 0.35 & & 0.36 & 0.34 \\
0.28 & 0.31 & 0.31 & & 0.32 & 0.33 \\
0.56 & 0.30 & 0.30 & & 0.32 & 0.25 \\
0.79 & 0.29 & 0.31 & & 0.33 & 0.26 \\
1.12 & 0.30 & 0.31 & & 0.35 & 0.25 \\
2.24 & 0.34 & 0.29 & & 0.34 & 0.23 \\
4.47 & 0.33 & 0.26 & & 0.27 & 0.23 \\
8.91 & 0.32 & 0.27 & & 0.26 & 0.23 \\
12.6 & 0.30 & 0.26 & & 0.26 & 0.22 \\
\hline
\end{tabular}

*In $\log _{10}$ units, based on variability of the California ground motion database about the predictions. those of Abrahamson and Silva (1997). For example, Abrahamson and Silva have $\sigma$ of 0.28 and 0.22 ( $\log _{10}$ units) for large events, for frequencies of 0.5 and $5 \mathrm{~Hz}$, respectively. For the stochastic relations, we obtain values of 0.25 and 0.23 , for frequencies of 0.5 and $5 \mathrm{~Hz}$, respectively, for soil sites. The corresponding values for rock sites ( 0.32 and 0.27 ) are slightly larger.

\section{Simple Equation Fit to Predictions}

The simulated ground-motion amplitudes can be fit to a simple functional form, for convenient use in seismic hazard analyses. Table 2 presents coefficients for an equation for response spectra at rock sites, in the form:

$$
\begin{aligned}
\log \mathrm{PSA}=c_{1} & +c_{2}(\mathbf{M}-6) \\
& +c_{3}(\mathbf{M}-6)^{2}-\log \mathrm{R}-c_{4} \mathrm{R}
\end{aligned}
$$


Table 2

Coefficients of the Ground Motion Relations for Generic Rock Sites $(\beta=620 \mathrm{~m} / \mathrm{sec})^{*}$

\begin{tabular}{ccccc}
\hline Frequency $(\mathrm{Hz})$ & $\mathrm{c}_{1}$ & $\mathrm{c}_{2}$ & $\mathrm{c}_{3}$ & $\mathrm{c}_{4}$ \\
\hline 0.1 & 1.416 & 0.943 & -0.0461 & 0.0 \\
0.2 & 2.031 & 0.888 & -0.0736 & 0.0 \\
0.32 & 2.228 & 0.858 & -0.0809 & 0.0 \\
0.5 & 2.628 & 0.795 & -0.107 & 0.0 \\
1. & 3.150 & 0.660 & -0.106 & 0.00062 \\
2. & 3.573 & 0.508 & -0.0760 & 0.00155 \\
3.2 & 3.776 & 0.431 & -0.0541 & 0.00247 \\
5. & 3.911 & 0.379 & -0.0391 & 0.00349 \\
10. & 3.944 & 0.328 & -0.0232 & 0.00464 \\
20. & 3.713 & 0.318 & -0.0228 & 0.00394 \\
PGA & 3.556 & 0.333 & -0.0270 & 0.00303 \\
PGV & 2.203 & 0.502 & -0.0207 & 0.00021 \\
\hline
\end{tabular}

$* \log$ PSA $=c_{1}+c_{2}(\mathbf{M}-6)+c_{3}(\mathbf{M}-6)^{2}-\log \mathrm{R}-\mathrm{c}_{4} \mathrm{R}$ where $R=\sqrt{ }\left(d^{2}+h^{2}\right), d$ is the closest distance to the fault $(\mathrm{km}), \mathbf{M}$ is moment magnitude, and $\log \mathrm{h}=-0.5+0.15 \mathrm{M}$

Note: for soil sites, the soil terms from the Appendix table must be added.

where $R=\sqrt{ }\left(d^{2}+h^{2}\right), d$ is the closest distance to the fault $(\mathrm{km})$, and $\log h=-0.5+0.15 \mathbf{M}$ (from equation (4)). (For soil sites, the soil terms from the Appendix table must be added.) The simulated amplitudes actually follow a more complicated shape, in which the attenuation coefficients are slightly magnitude dependent. However, the simple form is all that is required for hazard analyses, if we focus the fit on the magnitude and distance range of engineering interest. Accordingly, we fit the amplitudes for events of $\mathbf{M} 5$ through $\mathbf{M}$ 8. For events of $\mathbf{M} \geq 7$, we include the simulation results for the entire distance range (1 to $200 \mathrm{~km}$ ). For smaller events $(5 \leq \mathbf{M}<7$ ), we include simulation results only for fault distances of $30 \mathrm{~km}$ and less $(\mathrm{d} \leq 30 \mathrm{~km})$.

The resulting fit is accurate for magnitudes 5 through 8 at close distances, but mildly overpredicts amplitudes from small events $(\mathbf{M}<6)$ at distances of $30 \mathrm{~km}$ and greater; this is because the attenuation shape is controlled by the relatively slow attenuation that applies to large-magnitude earthquakes. Figure 11 illustrates the degree of fit for a sample frequency $(3.2 \mathrm{~Hz})$; results are similar for other frequencies. The slight overprediction of amplitudes for small, distant earthquakes has no impact on seismic hazard analyses, since the hazard contributions are not significant in this magnitude-distance range (Atkinson and Boore, 1995).

\section{Conclusions}

Ground-motion relations have been developed for California based on a stochastic model, which combines the main advantages of both point-source and finite-fault modeling approaches. The proposed ground-motion relations, tabulated in the Appendix for rock and soil sites, and provided in equation form in Table 1 for rock sites, are in good agreement with the empirical strong-motion database for California. They agree well with empirical regression equations

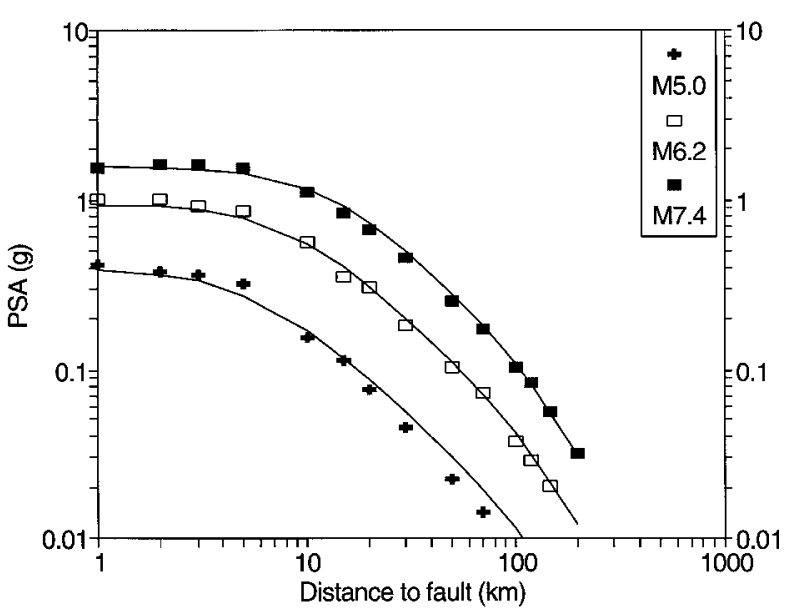

Figure 11. Example of fit of the quadratic groundmotion equations of Table 1 (lines) to the simulated ground motion amplitudes (symbols), for frequency $3.2 \mathrm{~Hz}$, for magnitudes 5.0, 6.2, and 7.4. The conservatism of the fit at small magnitudes and large distances is intentional, in order to get a good fit in the magnitude-distance range of interest, with a simple functional form.

(e.g., Abrahamson and Silva, 1997; Boore et al., 1997; Sadigh et al., 1997) in the magnitude-distance ranges that are well represented by the strong-motion database. The stochastic ground motion relations are underpinned by a source model that has been validated for earthquakes from magnitudes 4 through 8 (e.g., Silva et al., 1990; Schneider et al., 1993; Silva and Darragh, 1995; Beresnev and Atkinson, 1997, 1998a, 1998b, 1999). The attenuation model is derived from regional seismographic data over distances of hundreds of $\mathrm{km}$ (Raoof et al., 1999). The relations are in good agreement with the existing California strong-motion database. Therefore the stochastic ground-motion relations provide a sound basis for estimation of ground motions for earthquakes of magnitude 4 through 8 , at distances from a few to several hundred $\mathrm{km}$ of the source.

\section{Acknowledgments}

This study was supported by Grant 1434-HQ-97-GR-03061 from the National Earthquake Hazards Reduction Program. We thank Norm Abrahamson, Dave Boore, Tom Hanks, and Bill Joyner for stimulating discussions; Dave Boore, Alexei Tumarkin, and an anonymous reviewer provided constructive review comments on the draft manuscript.

\section{References}

Abrahamson, N., and W. Silva (1997). Empirical response spectral attenuation relations for shallow crustal earthquakes, Seism. Res. Lett. 68, 94-127.

Abrahamson, N. A., P. G. Somerville, and C. A. Cornell (1990). Uncertainty in numerical strong motion predictions, in Proceedings of the Fourth U.S. National Conference on Earthquake Engineering, Palm Springs, California, Vol. 1, 407-416.

Anderson, J., and S. Hough (1984). A model for the shape of the Fourier 
amplitude spectrum of acceleration at high frequencies, Bull. Seism. Soc. Am. 74, 1969-1993.

Atkinson, G. M. (1984). Attenuation of strong ground motion in Canada from a random vibrations approach, Bull. Seism. Soc. Am. 74, 26292653.

Atkinson, G. M. (1993). Earthquake source spectra in eastern North America, Bull. Seism. Soc. Am. 83, 1778-1798.

Atkinson, G. M., and D. M. Boore (1995). Ground-motion relations for eastern North America, Bull. Seism. Soc. Am. 85, 17-30.

Atkinson, G. M., and D. M. Boore (1998). Evaluation of models for earthquake source spectra in eastern North America, Bull. Seism. Soc. Am. 88, 917-934.

Atkinson, G. M., and W. Silva (1997). An empirical study of earthquake source spectra for California earthquakes, Bull. Seism. Soc. Am. 87, 97-113.

Beresnev, I. A., and G. M. Atkinson (1997). Modeling finite-fault radiation from the $\omega^{\mathrm{n}}$ spectrum, Bull. Seism. Soc. Am. 87, 67-84.

Beresnev, I. A., and G. M. Atkinson (1998a). FINSIM-a FORTRAN program for simulating stochastic acceleration time histories from finite faults, Seism. Res. Lett. 69, 27-32.

Beresnev, I. A., and G. M. Atkinson (1998b). Stochastic finite-fault modeling of ground motions from the 1994 Northridge, California, earthquake. I. Validation on rock sites, Bull. Seism. Soc. Am. 88, 13921401.

Beresnev, I. and G. Atkinson (1999). Generic finite-fault model for ground motion prediction in eastern North America, Bull. Seism. Soc. Am. 89, 608-625.

Boatwright, J., and G. L. Choy (1992). Acceleration source spectra anticipated for large earthquakes in northeastern North America, Bull. Seism. Soc. Am. 82, 660-682.

Boore, D. M. (1983). Stochastic simulation of high-frequency ground motions based on seismological models of the radiated spectra, Bull. Seism. Soc. Am. 73, 1865-1894.

Boore, D. (1996). SMSIM-Fortran program for simulating ground motions from earthquakes: Version 1.0, U.S. Geol. Surv. Open-File Rept. 96-80-A.

Boore, D. M., and G. M. Atkinson (1987). Stochastic prediction of ground motion and spectral response parameters at hard-rock sites in eastern North America, Bull. Seism. Soc. Am. 77, 440-467.

Boore, D. and G. Atkinson (1992). Source spectra for the 1988 Saguenay, Quebec, earthquakes, Bull. Seism. Soc. Am. 82, 683-719.

Boore, D. M., and W. B. Joyner (1997). Site amplifications for generic rock sites, Bull. Seism. Soc. Am. 87, 327-341.

Boore, D., W. Joyner, and T. Fumal (1997). Equations for estimating horizontal response spectra and peak acceleration from western North American earthquakes: a summary of recent work, Seism. Res. Lett. 68, 128-153.

Boore, D., W. Joyner, and L. Wennerberg (1992). Fitting the stochastic omega-squared source model of observed response spectra in western North America, Bull. Seism. Soc. Am. 82, 1956-1963.

Brune, J. N. (1970). Tectonic stress and the spectra of seismic shear waves from earthquakes, J. Geophys. Res. 75, 4997-5009.

Brune, J. (1971). Correction, J. Geophys. Res. 76, 5002.

Durwand, J., D. Boore, and W. Joyner (1996). The amplitude dependence of high-frequency spectral decay: constraint on soil non-linearity, Proc. Intl. Workshop on Site Response Subjected to Strong Earthquake Motions, Yokosuka, Japan, 16-17 January.
EPRI (1993). Guidelines for Determining Design Basis Ground Motions. Early Site Permit Demonstration Program, Vol. 1, RP3302, Electric Power Research Institute, Palo Alto, California.

Hanks, T. C., and R. K. McGuire (1981). The character of high-frequency strong ground motion, Bull. Seism. Soc. Am. 71 2071-2095.

Hartzell, S. (1978). Earthquake aftershocks as Green's functions, Geophys. Res. Lett. 5, 1-14.

Joyner, W., and D. Boore (1986). On simulating large earthquakes by Green's-function addition of smaller earthquakes, in Proceedings of the Fifth Maurice Ewing Symposium on Earthquake Source Mechanics, S. Das, J. Boatwright, and C. Scholz (Editors), Am. Geophys. Union, 269-274.

Ni, S., J. Anderson, Y. Zeng, and R. Siddharthan (2000). Expected signature of nonlinearity on regression for strong ground motion parameters. Bull. Seism. Soc. Am. 90 (in press).

Raoof, M., R. Herrmann, and L. Malagnini (1999). Attenuation and excitation of three-component ground motion in southern California, Bull. Seism. Soc. Am., 89, 888-902.

Sadigh, K., C. Chang, J. Egan, F. Makdisi, and R. Youngs (1997). Attenuation relationships for shallow crustal earthquakes based on California strong motion data, Seism. Res. Lett. 68, 180-189.

Schneider, J. F., W. J. Silva, and C. Stark (1993). Ground motion model for the $1989 M 6.9$ Loma Prieta earthquake including effects of source, path, and site, Earthquake Spectra 9, 251-287.

Silva, W. and R. Darragh (1995). Engineering Characterization of Earthquake Strong Ground Motion Recorded at Rock Sites, Electric Power Research Institute, Report TR-102261, Palo Alto, California.

Silva, W., R. Darragh, and I. Wong (1990). Engineering characterization of earthquake strong ground motions with applications to the Pacific Northwest, in Proc. Third NEHRP Workshop on earthquake hazards in the Puget Sound/Portland region, W. Hays (Editor), U.S. Geol. Surv. Open-File Rept.

Silva, W., and C. Stark (1992). Source, path, and site ground motion model for the 1989 M 6.9 Loma Prieta earthquake. Report to California Division of Mines and Geology.

Toro, G. R., N. A. Abrahamson, and J. F. Schneider (1997). Model of strong ground motions from earthquakes in central and eastern North America: best estimates and uncertainties, Seism. Res. Lett. 68, 41-57.

Wells, D., and K. Coppersmith (1994). New empirical relationships among magnitude, rupture length, rupture width, rupture area, and surface displacement, Bull. Seism. Soc. Am. 84, 974-1002.

Department of Earth Sciences

Carleton University

1125 Colonel By Drive

Ottawa, Ontario K1S 5B6, Canada

E-mail gma@ccs.carleton.ca

(G. M. A.)

Pacific Engineering and Analysis

311 Pomona Ave.

El Cerrito, California 94530

(W. S.)

Manuscript received 28 April 1999. 
Appendix

Predicted Ground Motions for Rock Sites, from 2-Corner Equivalent Point-Source Model

\begin{tabular}{|c|c|c|c|c|c|c|c|c|c|c|c|c|c|}
\hline \multirow{2}{*}{$\begin{array}{c}\text { Moment } \\
\text { Magnitude }\end{array}$} & \multirow{2}{*}{$\begin{array}{c}\text { Fault } \\
\text { Distance }(\mathrm{km})\end{array}$} & \multicolumn{10}{|c|}{$\log$ values of PSA $\left(\mathrm{cm} / \mathrm{sec}^{* *}\right)$ for freq: } & \multirow[b]{2}{*}{ PGA } & \multirow[b]{2}{*}{ PGV } \\
\hline & & .10 & .20 & .32 & .50 & 1.00 & 2.00 & 3.20 & 5.00 & 10.00 & $\overline{20.00}$ & & \\
\hline 4.00 & 1.0 & -.959 & -.347 & -.149 & .230 & .875 & 1.519 & 1.954 & 2.301 & 2.556 & 2.519 & 2.279 & .628 \\
\hline 4.00 & 2.0 & -1.167 & -.569 & -.377 & .000 & .672 & 1.415 & 1.845 & 2.230 & 2.519 & 2.398 & 2.196 & .494 \\
\hline 4.00 & 3.0 & -1.071 & -.481 & -.276 & .114 & .740 & 1.431 & 1.839 & 2.204 & 2.531 & 2.322 & 2.173 & .512 \\
\hline 4.00 & 5.0 & -1.229 & -.620 & -.432 & -.027 & 613 & 1.255 & 1.653 & 1.964 & 2.301 & 2.204 & 2.004 & .305 \\
\hline 4.00 & 10.0 & -1.585 & -1.000 & -.796 & -.387 & .255 & .919 & 1.342 & 1.740 & 2.041 & 1.940 & 1.733 & .025 \\
\hline 4.00 & 15.0 & -1.745 & -1.137 & -.921 & -.523 & .176 & .845 & 1.230 & 1.491 & 1.681 & 1.568 & 1.344 & -.296 \\
\hline 4.00 & 20.0 & -2.000 & -1.387 & -1.174 & -.721 & -.009 & .690 & .978 & 1.322 & 1.613 & 1.415 & 1.190 & -.484 \\
\hline 4.00 & 30.0 & -2.180 & -1.553 & -1.337 & -.921 & -.174 & .519 & .869 & 1.176 & 1.230 & 1.079 & .869 & -.730 \\
\hline 4.00 & 50.0 & -2.456 & -1.824 & -1.620 & -1.125 & -.432 & .176 & .568 & .806 & .924 & .633 & .486 & -1.025 \\
\hline 4.00 & 70.0 & -2.602 & -1.959 & -1.745 & -1.284 & -.638 & .079 & .362 & .531 & .643 & .362 & .223 & -1.226 \\
\hline 4.00 & 100.0 & -2.854 & -2.229 & -2.000 & -1.432 & -.854 & -.215 & .114 & .279 & .279 & .000 & -.080 & -1.469 \\
\hline 4.00 & 120.0 & -2.959 & -2.319 & -2.046 & -1.602 & -.921 & -.319 & -.009 & .114 & .041 & -.237 & -.296 & -1.475 \\
\hline 4.00 & 150.0 & -3.108 & -2.387 & -2.174 & -1.745 & -1.036 & -.509 & -.229 & -.114 & -.201 & -.481 & -.548 & -1.684 \\
\hline 4.00 & 200.0 & -3.215 & -2.569 & -2.319 & -1.824 & -1.229 & -.745 & -.509 & -.444 & -.620 & -.796 & -.845 & -1.636 \\
\hline 4.20 & 1.0 & -.854 & -.260 & -.066 & .322 & .964 & 1.633 & 2.000 & 2.342 & 2.643 & 2.556 & 2.314 & .654 \\
\hline 4.20 & 2.0 & -.824 & -.244 & -.041 & .380 & 1.041 & 1.663 & 2.079 & 2.380 & 2.623 & 2.519 & 2.272 & .667 \\
\hline 4.20 & 3.0 & -.959 & -.347 & -.143 & .255 & .881 & 1.544 & 1.940 & 2.342 & 2.663 & 2.447 & 2.303 & .640 \\
\hline 4.20 & 5.0 & -1.066 & -.469 & -.276 & .114 & .799 & 1.462 & 1.892 & 2.255 & 2.462 & 2.279 & 2.146 & .522 \\
\hline 4.20 & 10.0 & -1.347 & -.745 & -.553 & -.143 & .491 & 1.146 & 1.602 & 1.914 & 2.146 & 2.041 & 1.810 & .164 \\
\hline 4.20 & 15.0 & -1.538 & -.921 & -.721 & -2.84 & .380 & 1.114 & 1.415 & 1.732 & 1.886 & 1.672 & 1.476 & -.094 \\
\hline 4.20 & 20.0 & -1.770 & -1.149 & -.921 & -.509 & .146 & .839 & 1.176 & 1.505 & 1.699 & 1.531 & 1.303 & -.323 \\
\hline 4.20 & 30.0 & -1.921 & -1.292 & -1.076 & -.602 & .079 & .663 & 1.041 & 1.301 & 1.415 & 1.204 & 1.025 & -.530 \\
\hline 4.20 & 50.0 & -2.222 & -1.585 & -1.367 & -.921 & -.237 & .398 & .724 & .973 & 1.041 & .785 & .624 & -.903 \\
\hline 4.20 & 70.0 & -2.357 & -1.721 & -1.523 & -1.056 & -.347 & .204 & .556 & .748 & .771 & .477 & .356 & -1.063 \\
\hline 4.20 & 100.0 & -2.620 & -1.959 & -1.721 & -1.208 & -.553 & -.022 & .301 & .462 & .447 & .146 & .061 & -1.287 \\
\hline 4.20 & 120.0 & -2.638 & -2.000 & -1.745 & -1.268 & -.620 & -.076 & .146 & .301 & .204 & -.066 & -.143 & -1.405 \\
\hline 4.20 & 150.0 & -2.824 & -2.131 & -1.886 & -1.398 & -.824 & -.301 & -.027 & -.079 & -.027 & -.328 & -.380 & -1.530 \\
\hline 4.20 & 200.0 & -2.959 & -2.301 & -2.086 & -1.602 & -.959 & .5 & -.337 & -.276 & -.481 & -.678 & -.710 & -1.567 \\
\hline 4.40 & 1.0 & -.602 & -.013 & .176 & .591 & 1.230 & 1.881 & 2.279 & 2.531 & 2.699 & 2.591 & 2.423 & .843 \\
\hline 4.40 & 2.0 & -.678 & -.086 & .114 & .505 & 1.176 & 1.826 & 2.176 & 2.477 & 2.699 & 2.531 & 2.334 & .725 \\
\hline 4.40 & 3.0 & -.745 & -.161 & .041 & .431 & 1.079 & 1.653 & 2.041 & 2.415 & 2.613 & 2.531 & 2.307 & .654 \\
\hline 4.40 & 5.0 & -.796 & -.201 & -.013 & .380 & 1.041 & 1.613 & 2.041 & 2.362 & 2.580 & 2.380 & 2.220 & .600 \\
\hline 4.40 & 10.0 & -1.086 & -.495 & -.292 & .146 & .806 & 1.431 & 1.857 & 2.146 & 2.204 & 2.114 & 1.927 & .350 \\
\hline 4.40 & 15.0 & -1.337 & -.721 & -.509 & -.051 & .613 & 1.204 & 1.544 & 1.881 & 1.968 & 1.806 & 1.593 & .004 \\
\hline 4.40 & 20.0 & -1.509 & -.886 & -.699 & -.244 & .447 & 1.041 & 1.415 & 1.643 & 1.820 & 1.580 & 1.400 & -.169 \\
\hline 4.40 & 30.0 & -1.745 & -1.108 & -.886 & -.398 & .301 & .857 & 1.146 & 1.415 & 1.568 & 1.322 & 1.137 & -.412 \\
\hline 4.40 & 50.0 & -2.013 & -1.387 & -1.161 & -.678 & .041 & .602 & .959 & 1.114 & 1.176 & .875 & .736 & -.708 \\
\hline 4.40 & 70.0 & -2.174 & -1.509 & -1.260 & -.796 & -.180 & .380 & .633 & .919 & .929 & .591 & .508 & -.928 \\
\hline 4.40 & 100.0 & -2.301 & -1.658 & -1.469 & -.959 & -.337 & -.176 & .505 & .633 & .591 & .279 & .204 & -1.100 \\
\hline 4.40 & 120.0 & -2.456 & -1.770 & -1.553 & -1.051 & -.4 & .079 & .301 & .477 & .322 & .041 & .004 & -1.210 \\
\hline 4.40 & 150.0 & -2.509 & -1.796 & -1.569 & -1.131 & -.620 & -.114 & .079 & .230 & .041 & -.208 & -.251 & -1.361 \\
\hline 4.40 & 200.0 & -2.699 & -2.018 & -1.796 & -1.357 & -.796 & -.319 & -.180 & -.143 & -.357 & -.509 & -.567 & -1.400 \\
\hline 4.60 & 1.0 & -.432 & .176 & .380 & .820 & 1.431 & 2.041 & 2.342 & 2.591 & 2.785 & 2.623 & 2.453 & .873 \\
\hline 4.60 & 2.0 & -.538 & .041 & .255 & .699 & 1.342 & 1.968 & 2.322 & 2.602 & 2.806 & 2.681 & 2.430 & .829 \\
\hline 4.60 & 3.0 & -.638 & -.046 & .146 & .580 & 1.255 & 1.914 & 2.279 & 2.580 & 2.681 & 2.623 & 2.352 & .786 \\
\hline 4.60 & 5.0 & -.620 & -.027 & .176 & .556 & 1.255 & 1.940 & 2.230 & 2.477 & 2.613 & 2.398 & 2.307 & .754 \\
\hline 4.60 & 10.0 & -.886 & -.292 & -.102 & .322 & .987 & 1.708 & 2.041 & 2.230 & 2.380 & 2.146 & 2.009 & .462 \\
\hline 4.60 & 15.0 & -1.097 & -.481 & -.268 & .146 & .833 & 1.431 & 1.740 & 1.982 & 2.114 & 1.898 & 1.723 & .201 \\
\hline 4.60 & 20.0 & -1.301 & -.699 & -.481 & -.036 & .681 & 1.204 & 1.544 & 1.875 & 1.898 & 1.681 & 1.554 & -.008 \\
\hline 4.60 & 30.0 & -1.523 & -.854 & -.658 & -.143 & .431 & 1.041 & 1.322 & 1.505 & 1.633 & 1.380 & 1.207 & -.285 \\
\hline 4.60 & 50.0 & -1.796 & -1.137 & -.921 & -.444 & .230 & .732 & 1.041 & 1.279 & 1.255 & 1.000 & .866 & -.570 \\
\hline 4.60 & 70.0 & -1.921 & -1.237 & -1.036 & -.509 & .079 & .544 & .857 & 1.079 & 1.041 & .724 & .635 & -.772 \\
\hline 4.60 & 100.0 & -2.119 & -1.398 & -1.174 & -.770 & -.081 & .431 & .580 & .771 & .681 & .380 & .314 & -.979 \\
\hline 4.60 & 120.0 & -2.161 & -1.456 & -1.260 & -.796 & -.260 & .255 & .519 & .602 & .462 & .176 & .149 & -1.120 \\
\hline 4.60 & 150.0 & -2.284 & -1.569 & -1.319 & -.886 & -.328 & .114 & .301 & .380 & .204 & -.056 & -.093 & -1.197 \\
\hline 4.60 & 200.0 & -2.469 & -1.745 & -1.569 & -1.194 & -.585 & -.131 & -.018 & -.004 & -.229 & -.409 & -.437 & -1.434 \\
\hline 4.80 & 1.0 & -.357 & .230 & .431 & .869 & 1.477 & 2.114 & 2.568 & 2.756 & 2.892 & 2.716 & 2.537 & 1.004 \\
\hline 4.80 & 2.0 & -.398 & .230 & .431 & .881 & 1.519 & 2.176 & 2.447 & 2.708 & 2.839 & 2.653 & 2.498 & .968 \\
\hline 4.80 & 3.0 & -.377 & .204 & .398 & .845 & 1.531 & 2.146 & 2.491 & 2.681 & 2.820 & 2.602 & 2.413 & .941 \\
\hline 4.80 & 5.0 & -.553 & .041 & .279 & .716 & 1.342 & 1.929 & 2.342 & 2.568 & 2.740 & 2.519 & 2.367 & .779 \\
\hline 4.80 & 10.0 & -.721 & -.137 & .041 & .462 & 1.114 & 1.724 & 2.000 & 2.342 & 2.462 & 2.255 & 2.090 & .567 \\
\hline
\end{tabular}




\begin{tabular}{|c|c|c|c|c|c|c|c|c|c|c|c|c|c|}
\hline 4.80 & 15.0 & -1.022 & -.409 & -.180 & .301 & .968 & 1.568 & 1.978 & 2.079 & 2.204 & 1.954 & 1.826 & .312 \\
\hline 4.80 & 20.0 & -1.081 & -.409 & -.167 & .230 & .763 & 1.415 & 1.681 & 1.949 & 2.000 & 1.785 & 1.601 & .10 \\
\hline 4.80 & 30.0 & -1.319 & -.658 & -.420 & .041 & .663 & 1.230 & 1.491 & 1.663 & 1.724 & 1.447 & 1.322 & -.09 \\
\hline 4.80 & 50.0 & -1.553 & -.886 & -.678 & -.201 & .447 & 1.000 & 1.176 & 1.415 & 1.415 & 1.114 & 1.025 & -.41 \\
\hline 4.80 & 70.0 & -1.658 & -1.009 & -.770 & -.292 & .255 & .763 & 1.041 & 1.114 & 1.114 & .820 & .729 & -.600 \\
\hline 4.80 & 100.0 & -1.824 & -1.201 & -1.000 & -.456 & .079 & .544 & .833 & .914 & .792 & .505 & .441 & -.83 \\
\hline 4.80 & 120.0 & -1.886 & -1.187 & -.959 & -.481 & -.004 & .462 & .653 & .708 & .613 & .322 & .276 & -.9 \\
\hline 4.80 & 150.0 & -2.060 & -1.367 & -1.161 & -.699 & -.108 & .322 & .477 & .519 & .301 & .079 & .037 & -1.0 \\
\hline 4.80 & 200.0 & -2.174 & -1.377 & -1.222 & -.854 & -.357 & .041 & .146 & .146 & -.119 & -.268 & -.271 & -1.2 \\
\hline 5.00 & 1.0 & -.155 & .431 & .633 & 1.079 & 1.732 & 2.255 & 2.602 & 2.785 & 2.881 & 2.763 & 2.542 & 1.0 \\
\hline 5.00 & 2.0 & -.167 & .431 & .633 & 1.079 & 1.633 & 2.255 & 2.568 & 2.732 & 2.934 & 2.699 & 2.544 & 1.0 \\
\hline 5.00 & 3.0 & -.284 & .342 & .580 & .982 & 1.591 & 2.176 & 2.544 & 2.716 & 2.845 & 2.672 & 2.487 & \\
\hline 5.00 & 5.0 & -.398 & .204 & .398 & .820 & 1.462 & 2.114 & 2.491 & 2.580 & 2.740 & 2.568 & 2.375 & .8 \\
\hline 5.00 & 10.0 & -.509 & .114 & .342 & .763 & 1.362 & 1.949 & 2.176 & 2.431 & 2.544 & 2.301 & 2.130 & .68 \\
\hline 5.00 & 15.0 & -.770 & -.137 & .079 & .505 & 1.146 & 1.756 & 2.041 & 2.176 & 2.255 & 2.041 & 1.861 & .40 \\
\hline 5.00 & 20.0 & -.959 & -.319 & -.108 & .322 & 1.041 & 1.623 & 1.875 & 2.079 & 2.114 & 1.845 & 1.696 & .2 \\
\hline 5.00 & 30.0 & -1.119 & -.469 & -.252 & .176 & .699 & 1.362 & 1.643 & 1.799 & 1.863 & 1.580 & 1.427 & .00 \\
\hline 5.00 & 50.0 & -1.276 & -.658 & -.444 & .000 & .580 & 1.114 & 1.342 & 1.447 & 1.477 & 1.204 & 1.121 & -.27 \\
\hline 5.00 & 70.0 & -1.444 & -.770 & -.569 & -.051 & .462 & .903 & 1.146 & 1.255 & 1.255 & .940 & .852 & -.46 \\
\hline 5.00 & 100.0 & -1.538 & -.886 & -.699 & -.301 & .322 & .732 & .978 & 1.000 & .914 & .623 & .572 & -.6 \\
\hline 5.00 & 120.0 & -1.699 & -1.056 & -.796 & -.310 & .230 & .623 & .792 & .851 & .690 & .431 & .394 & $-.7^{\prime}$ \\
\hline 5.00 & 150.0 & -1.770 & -1.092 & -.824 & -.469 & .041 & .447 & .580 & .643 & .415 & .204 & .173 & -.9 \\
\hline 5.00 & 200.0 & -2.000 & -1.292 & -1.076 & -.699 & -.131 & .204 & .301 & .279 & .041 & -.102 & -.130 & -1.1 \\
\hline 5.20 & 1.0 & -.092 & .531 & .756 & 1.176 & 1.898 & 2.447 & 2.602 & 2.839 & 3.041 & 2.820 & 2.607 & 1.137 \\
\hline 5.20 & 2.0 & -.036 & .568 & .785 & 1.230 & 1.914 & 2.380 & 2.672 & 2.806 & 2.987 & 2.732 & 2.597 & 1.140 \\
\hline 5.20 & 3.0 & -.137 & .491 & .708 & 1.114 & 1.763 & 2.322 & 2.602 & 2.903 & 2.881 & 2.748 & 2.565 & 1.053 \\
\hline 5.20 & 5.0 & -.222 & .398 & .613 & 1.079 & 1.724 & 2.322 & 2.544 & 2.716 & 2.813 & 2.633 & 2.442 & .98 \\
\hline 5.20 & 10.0 & -.409 & .230 & .462 & .903 & 1.505 & 1.996 & 2.342 & 2.531 & 2.633 & 2.398 & 2.246 & .7 \\
\hline 5.20 & 15.0 & -.569 & .079 & .279 & .681 & 1.279 & 1.839 & 2.146 & 2.342 & 2.279 & 2.114 & 1.949 & \\
\hline 5.20 & 20.0 & -.721 & -.041 & .176 & .591 & 1.146 & 1.732 & 1.973 & 2.146 & 2.176 & 1.959 & 1.836 & \\
\hline 5.20 & 30.0 & -.886 & -.215 & -.013 & .505 & .929 & 1.431 & 1.813 & 1.903 & 1.968 & 1.663 & 1.530 & \\
\hline 5.20 & 50.0 & -1.161 & -.469 & -.252 & .176 & .724 & 1.204 & 1.431 & 1.580 & 1.568 & 1.301 & 1.182 & -.17 \\
\hline 5.20 & 70.0 & -1.260 & -.638 & -.420 & .041 & .672 & 1.079 & 1.279 & 1.322 & 1.301 & 1.041 & .960 & -.32 \\
\hline 5.20 & 100.0 & -1.377 & -.745 & -.538 & -.066 & .519 & .934 & 1.114 & 1.146 & .996 & .748 & .700 & -.50 \\
\hline 5.20 & 120.0 & -1.495 & -.770 & -.602 & -.167 & .301 & .771 & .934 & .968 & .820 & .531 & .517 & -.6 \\
\hline 5.20 & 150.0 & -1.538 & -.854 & -.638 & -.260 & .204 & .653 & .716 & .778 & .568 & .322 & .314 & -.764 \\
\hline 5.20 & 200.0 & -1.678 & -1.000 & -.824 & -.357 & .114 & .301 & .431 & .415 & .176 & .041 & .029 & -.943 \\
\hline 5.40 & 1.0 & .079 & .763 & .978 & 1.398 & 2.041 & 2.556 & 2.771 & 2.968 & 3.000 & 2.813 & 2.665 & 1.22 \\
\hline 5.40 & 2.0 & .041 & .672 & .886 & 1.342 & 1.959 & 2.568 & 2.785 & 2.903 & 2.964 & 2.778 & 2.642 & 1.207 \\
\hline 5.40 & 3.0 & .041 & .699 & .919 & 1.362 & 1.949 & 2.505 & 2.763 & 2.886 & 2.959 & 2.732 & 2.594 & 1.185 \\
\hline 5.40 & 5.0 & -.066 & .556 & .763 & 1.176 & 1.924 & 2.342 & 2.556 & 2.763 & 2.898 & 2.623 & 2.505 & 1.06 \\
\hline 5.40 & 10.0 & -.260 & .380 & .580 & .991 & 1.663 & 2.204 & 2.431 & 2.602 & 2.672 & 2.447 & 2.303 & .8 \\
\hline 5.40 & 15.0 & -.409 & .204 & .431 & .886 & 1.519 & 2.041 & 2.204 & 2.380 & 2.362 & 2.176 & 2.041 & 6 \\
\hline 5.40 & 20.0 & -.523 & .146 & .362 & .826 & 1.380 & 1.845 & 2.041 & 2.204 & 2.279 & 2.041 & 1.880 & .4 \\
\hline 5.40 & 30.0 & -.721 & -.060 & .176 & .580 & 1.204 & 1.643 & 1.826 & 1.991 & 2.000 & 1.771 & 1.639 & \\
\hline 5.40 & 50.0 & -.886 & -.222 & -.046 & .342 & .949 & 1.447 & 1.580 & 1.681 & 1.672 & 1.398 & 1.279 & -.0 \\
\hline 5.40 & 70.0 & -.959 & -.319 & -.155 & .255 & .792 & 1.204 & 1.431 & 1.505 & 1.415 & 1.146 & 1.079 & -.1 \\
\hline 5.40 & 100.0 & -1.167 & -.456 & -.292 & .079 & .602 & 1.000 & 1.230 & 1.230 & 1.079 & .813 & .768 & -.382 \\
\hline 5.40 & 120.0 & -1.284 & -.658 & -.367 & .000 & .544 & .886 & 1.041 & 1.079 & .924 & .663 & .627 & -.483 \\
\hline 5.40 & 150.0 & -1.337 & -.585 & -.377 & -.036 & .380 & .756 & .898 & .881 & .623 & .447 & .422 & -.63 \\
\hline 5.40 & 200.0 & -1.377 & -.721 & -.602 & -.268 & .204 & .491 & .568 & .477 & .230 & .114 & .107 & -.860 \\
\hline 5.60 & 1.0 & .230 & .857 & 1.041 & 1.505 & 2.146 & 2.580 & 2.748 & 2.982 & 3.041 & 2.869 & 2.667 & 1.23 \\
\hline 5.60 & 2.0 & .204 & .851 & 1.041 & 1.431 & 2.041 & 2.580 & 2.771 & 2.973 & 3.000 & 2.820 & 2.669 & 1.2 \\
\hline 5.60 & 3.0 & .204 & .833 & 1.041 & 1.477 & 2.079 & 2.568 & 2.826 & 2.919 & 2.929 & 2.778 & 2.620 & $1.26^{\circ}$ \\
\hline 5.60 & 5.0 & .146 & .785 & .987 & 1.398 & 1.940 & 2.477 & 2.672 & 2.908 & 2.919 & 2.699 & 2.522 & 1.14 \\
\hline 5.60 & 10.0 & -.114 & .531 & .748 & 1.176 & 1.763 & 2.230 & 2.568 & 2.708 & 2.690 & 2.477 & 2.332 & .94 \\
\hline 5.60 & 15.0 & -.229 & .462 & .690 & 1.041 & 1.653 & 2.146 & 2.322 & 2.431 & 2.505 & 2.279 & 2.121 & \\
\hline 5.60 & 20.0 & -.409 & .230 & .447 & .944 & 1.491 & 1.919 & 2.146 & 2.342 & 2.322 & 2.079 & 1.957 & \\
\hline 5.60 & 30.0 & -.495 & .146 & .380 & .763 & 1.322 & 1.785 & 2.041 & 2.079 & 2.114 & 1.833 & 1.725 & .40 \\
\hline 5.60 & 50.0 & -.638 & -.056 & .114 & .447 & 1.041 & 1.462 & 1.716 & 1.792 & 1.699 & 1.477 & 1.391 & .07 \\
\hline 5.60 & 70.0 & -.824 & -.125 & .114 & .462 & .968 & 1.362 & 1.491 & 1.556 & 1.462 & 1.204 & 1.152 & -.05 \\
\hline 5.60 & 100.0 & -.959 & -.347 & -.180 & .230 & .833 & 1.146 & 1.279 & 1.362 & 1.230 & .949 & .911 & -.23 \\
\hline 5.60 & 120.0 & -.959 & -.292 & -.102 & .301 & .699 & 1.041 & 1.146 & 1.146 & 1.000 & .778 & .760 & -.335 \\
\hline 5.60 & 150.0 & -1.046 & -.347 & -.187 & .114 & .544 & .845 & .944 & .919 & .732 & .544 & .530 & -.480 \\
\hline 5.60 & 200.0 & -1.155 & -.509 & -.387 & -.018 & .415 & .653 & .708 & .613 & .380 & .301 & .281 & -.672 \\
\hline 5.80 & 1.0 & .362 & .973 & 1.230 & 1.672 & 2.204 & 2.699 & 2.851 & 3.079 & 3.079 & 2.863 & 2.709 & 1.334 \\
\hline 5.80 & 2.0 & .415 & 1.041 & 1.255 & 1.663 & 2.255 & 2.653 & 2.892 & 3.041 & 3.041 & 2.881 & 2.712 & \\
\hline
\end{tabular}




\begin{tabular}{|c|c|c|c|c|c|c|c|c|c|c|c|c|c|}
\hline 5.80 & 3.0 & .398 & 1.079 & 1.279 & 1.699 & 2.230 & 2.613 & 2.886 & 2.996 & 3.000 & 2.820 & 2.691 & 1.314 \\
\hline 5.80 & 5.0 & .301 & .934 & 1.114 & 1.556 & 2.114 & 2.531 & 2.857 & 2.959 & 2.987 & 2.785 & 2.617 & 1.248 \\
\hline 5.80 & 10.0 & .146 & .813 & 1.041 & 1.431 & 1.875 & 2.380 & 2.633 & 2.799 & 2.771 & 2.591 & 2.401 & 1.045 \\
\hline 5.80 & 15.0 & -.056 & .568 & .771 & 1.230 & 1.826 & 2.279 & 2.380 & 2.519 & 2.580 & 2.342 & 2.199 & .905 \\
\hline 5.80 & 20.0 & -.167 & .477 & .716 & 1.146 & 1.663 & 2.079 & 2.279 & 2.447 & 2.431 & 2.176 & 2.061 & .700 \\
\hline 5.80 & 30.0 & -.260 & .342 & .556 & .898 & 1.519 & 1.949 & 2.079 & 2.176 & 2.146 & 1.934 & 1.794 & .513 \\
\hline 5.80 & 50.0 & -.495 & .079 & .279 & .756 & 1.301 & 1.663 & 1.771 & 1.886 & 1.826 & 1.556 & 1.487 & .26 \\
\hline 5.80 & 70.0 & -.481 & .079 & .204 & .681 & 1.079 & 1.477 & 1.653 & 1.663 & 1.568 & 1.322 & 1.272 & .1 \\
\hline 5.80 & 100.0 & -.770 & -.092 & .079 & .447 & .978 & 1.301 & 1.398 & 1.415 & 1.255 & 1.041 & .997 & -.1 \\
\hline 5.80 & 120.0 & -.796 & -.155 & .000 & .380 & .851 & 1.176 & 1.301 & 1.255 & 1.079 & .875 & .852 & -.2 \\
\hline 5.80 & 150.0 & -.745 & -.268 & -.119 & .279 & .748 & .987 & 1.114 & 1.079 & .845 & .653 & .641 & -.3 \\
\hline 5.80 & 200.0 & -.886 & -.367 & -.215 & .146 & .580 & .763 & .792 & .699 & .491 & .398 & .384 & -.54 \\
\hline 6.00 & 1.0 & .672 & 1.301 & 1.462 & 1.863 & 2.398 & 2.724 & 2.949 & 3.079 & 3.114 & 2.892 & 2.728 & 1.4 \\
\hline 6.00 & 2.0 & .568 & 1.176 & 1.398 & 1.799 & 2.255 & 2.716 & 2.881 & 3.079 & 3.079 & 2.903 & 2.740 & 1.40 \\
\hline 6.00 & 3.0 & .613 & 1.255 & 1.462 & 1.748 & 2.322 & 2.732 & 2.954 & 3.041 & 3.079 & 2.851 & 2.708 & 1.41 \\
\hline 6.00 & 5.0 & .491 & 1.114 & 1.342 & 1.785 & 2.279 & 2.663 & 2.875 & 2.968 & 2.978 & 2.785 & 2.628 & 1.281 \\
\hline 6.00 & 10.0 & .279 & .892 & 1.079 & 1.544 & 2.041 & 2.505 & 2.690 & 2.833 & 2.839 & 2.643 & 2.487 & 1.140 \\
\hline 6.00 & 15.0 & .204 & .826 & .978 & 1.322 & 1.914 & 2.342 & 2.531 & 2.623 & 2.580 & 2.362 & 2.233 & .939 \\
\hline 6.00 & 20.0 & .041 & .672 & .839 & 1.255 & 1.699 & 2.176 & 2.398 & 2.505 & 2.462 & 2.255 & 2.117 & .827 \\
\hline 6.00 & 30.0 & -.032 & .519 & .653 & 1.146 & 1.602 & 1.996 & 2.146 & 2.255 & 2.230 & 1.954 & 1.838 & .6 \\
\hline 6.00 & 50.0 & -.301 & .301 & .544 & .929 & 1.431 & 1.799 & 1.845 & 2.000 & 1.898 & 1.653 & 1.574 & .3 \\
\hline 6.00 & 70.0 & -.420 & .255 & .447 & .813 & 1.279 & 1.653 & 1.690 & 1.724 & 1.672 & 1.398 & 1.344 & .2 \\
\hline 6.00 & 100.0 & -.495 & .079 & .322 & .643 & 1.114 & 1.415 & 1.477 & 1.491 & 1.362 & 1.114 & 1.068 & \\
\hline 6.00 & 120.0 & -.495 & -.013 & .176 & .568 & .964 & 1.255 & 1.380 & 1.342 & 1.146 & .973 & .949 & -.04 \\
\hline 6.00 & 150.0 & -.620 & -.041 & .146 & .531 & .857 & 1.146 & 1.146 & 1.146 & .929 & .763 & .746 & -.19 \\
\hline 6.00 & 200.0 & -.721 & -.194 & -.051 & .342 & .681 & .857 & .898 & .813 & .591 & .447 & .442 & -.40 \\
\hline 6.20 & 1.0 & .806 & 1.398 & 1.556 & 1.898 & 2.398 & 2.778 & 3.000 & 3.079 & 3.114 & 2.908 & 2.774 & 1.473 \\
\hline 6.20 & 2.0 & .672 & 1.301 & 1.531 & 1.826 & 2.362 & 2.748 & 3.000 & 3.041 & 3.146 & 2.924 & 2.727 & 1.430 \\
\hline 6.20 & 3.0 & .672 & 1.362 & 1.544 & 1.826 & 2.301 & 2.756 & 2.954 & 3.079 & 3.114 & 2.898 & 2.737 & 1.394 \\
\hline 6.20 & 5.0 & .505 & 1.146 & 1.342 & 1.708 & 2.322 & 2.690 & 2.929 & 3.000 & 3.079 & 2.820 & 2.675 & 1.3 \\
\hline 6.20 & 10.0 & .544 & 1.146 & 1.279 & 1.724 & 2.176 & 2.556 & 2.740 & 2.908 & 2.863 & 2.643 & 2.508 & 1.196 \\
\hline 6.20 & 15.0 & .380 & .982 & 1.176 & 1.580 & 2.041 & 2.362 & 2.531 & 2.681 & 2.681 & 2.462 & 2.324 & 1.029 \\
\hline 6.20 & 20.0 & .279 & .982 & 1.176 & 1.519 & 2.000 & 2.342 & 2.477 & 2.491 & 2.491 & 2.301 & 2.173 & .9 \\
\hline 6.20 & 30.0 & .041 & .613 & .792 & 1.204 & 1.778 & 2.114 & 2.255 & 2.342 & 2.279 & 2.041 & 1.957 & \\
\hline 6.20 & 50.0 & -.056 & .544 & 699 & 1.041 & 1.491 & 1.833 & 2.000 & 2.041 & 1.959 & 1.732 & 1.672 & \\
\hline 6.20 & 70.0 & -.155 & .362 & .591 & 1.000 & 1.415 & 1.708 & 1.851 & 1.869 & 1.732 & 1.477 & 1.423 & .3 \\
\hline 6.20 & 100.0 & -.229 & .230 & .477 & .820 & 1.204 & 1.544 & 1.568 & 1.568 & 1.415 & 1.204 & 1.196 & .1 \\
\hline 6.20 & 120.0 & -.284 & .146 & .398 & .763 & 1.146 & 1.380 & 1.447 & 1.431 & 1.279 & 1.079 & 1.057 & .0 \\
\hline 6.20 & 150.0 & -.432 & .114 & .301 & .531 & .996 & 1.176 & 1.301 & 1.230 & 1.000 & .881 & .856 & -.0 \\
\hline 6.20 & 200.0 & -.585 & -.022 & .146 & .398 & .813 & .968 & .954 & .875 & .681 & .591 & .582 & -.2 \\
\hline 6.40 & 1.0 & .845 & 1.477 & 1.663 & 2.041 & 2.462 & 2.898 & 3.079 & 3.114 & 3.146 & 2.929 & 2.779 & 1.5 \\
\hline 6.40 & 2.0 & .919 & 1.477 & 1.663 & 2.041 & 2.580 & 2.857 & 3.000 & 3.146 & 3.146 & 2.944 & 2.772 & 1.5 \\
\hline 6.40 & 3.0 & .863 & 1.491 & 1.663 & 2.000 & 2.477 & 2.886 & 3.000 & 3.114 & 3.146 & 2.903 & 2.776 & 1.5 \\
\hline 6.40 & 5.0 & .708 & 1.342 & 1.519 & 1.886 & 2.447 & 2.799 & 2.996 & 3.079 & 3.079 & 2.869 & 2.728 & 1.4 \\
\hline 6.40 & 10.0 & .690 & 1.255 & 1.462 & 1.903 & 2.322 & 2.732 & 2.813 & 2.924 & 2.940 & 2.690 & 2.561 & 1.3 \\
\hline 6.40 & 15.0 & .544 & 1.176 & 1.322 & 1.623 & 2.114 & 2.477 & 2.663 & 2.724 & 2.681 & 2.519 & 2.348 & 1.1 \\
\hline 6.40 & 20.0 & .362 & .919 & 1.146 & 1.505 & 2.000 & 2.322 & 2.519 & 2.591 & 2.613 & 2.322 & 2.201 & 1.0 \\
\hline 6.40 & 30.0 & .255 & .875 & 1.114 & 1.380 & 1.792 & 2.114 & 2.342 & 2.342 & 2.322 & 2.079 & 1.986 & .8 \\
\hline 6.40 & 50.0 & .114 & .672 & .857 & 1.114 & 1.623 & 1.954 & 2.041 & 2.079 & 2.041 & 1.785 & 1.714 & .57 \\
\hline 6.40 & 70.0 & -.009 & .580 & .681 & 1.041 & 1.505 & 1.813 & 1.863 & 1.914 & 1.792 & 1.580 & 1.534 & \\
\hline 6.40 & 100.0 & -.131 & .415 & .602 & .982 & 1.322 & 1.580 & 1.690 & 1.699 & 1.491 & 1.301 & 1.274 & .2 \\
\hline 6.40 & 120.0 & -.097 & .362 & .613 & .820 & 1.255 & 1.505 & 1.531 & 1.505 & 1.362 & 1.176 & 1.140 & .1 \\
\hline 6.40 & 150.0 & -.229 & .230 & .415 & .681 & 1.176 & 1.301 & 1.362 & 1.322 & 1.146 & .964 & .947 & .0 \\
\hline 6.40 & 200.0 & -.328 & .176 & .380 & .672 & .954 & 1.079 & 1.041 & .973 & .771 & .543 & .641 & -.1 \\
\hline 6.60 & 1.0 & .973 & 1.505 & 1.732 & 2.146 & 2.556 & 2.892 & 3.041 & 3.230 & 3.204 & 2.978 & 2.802 & 1.5 \\
\hline 6.60 & 2.0 & .929 & 1.519 & 1.732 & 2.230 & 2.602 & 2.914 & 3.114 & 3.146 & 3.146 & 2.964 & 2.787 & 1.5 \\
\hline 6.60 & 3.0 & .940 & 1.505 & 1.708 & 2.114 & 2.568 & 2.903 & 3.000 & 3.146 & 3.176 & 2.968 & 2.808 & 1.5 \\
\hline 6.60 & 5.0 & 1.041 & 1.633 & 1.833 & 2.114 & 2.544 & 2.903 & 2.996 & 3.079 & 3.114 & 2.892 & 2.749 & 1.5 \\
\hline 6.60 & 10.0 & .820 & 1.380 & 1.544 & 1.898 & 2.342 & 2.708 & 2.813 & 2.968 & 2.973 & 2.756 & 2.602 & 1.3 \\
\hline 6.60 & 15.0 & .708 & 1.230 & 1.415 & 1.806 & 2.255 & 2.580 & 2.716 & 2.799 & 2.792 & 2.544 & 2.425 & 1.2 \\
\hline 6.60 & 20.0 & .568 & 1.146 & 1.362 & 1.633 & 2.041 & 2.447 & 2.623 & 2.681 & 2.672 & 2.415 & 2.299 & 1.1 \\
\hline 6.60 & 30.0 & .431 & 1.000 & 1.114 & 1.505 & 1.934 & 2.322 & 2.431 & 2.447 & 2.447 & 2.176 & 2.079 & .9 \\
\hline 6.60 & 50.0 & .255 & .799 & 1.041 & 1.362 & 1.690 & 2.041 & 2.146 & 2.176 & 2.114 & 1.881 & 1.805 & .6 \\
\hline 6.60 & 70.0 & .230 & .732 & .908 & 1.176 & 1.623 & 1.851 & 1.973 & 2.000 & 1.857 & 1.633 & 1.580 & .5 \\
\hline 6.60 & 100.0 & .114 & .643 & .851 & 1.041 & 1.415 & 1.699 & 1.748 & 1.708 & 1.568 & 1.380 & 1.332 & \\
\hline 6.60 & 120.0 & .079 & .643 & .785 & 1.114 & 1.362 & 1.531 & 1.568 & 1.602 & 1.398 & 1.255 & 1.228 & .3 \\
\hline 6.60 & 150.0 & -.131 & .431 & .633 & .903 & 1.204 & 1.398 & 1.415 & 1.380 & 1.204 & 1.079 & 1.064 & .1 \\
\hline
\end{tabular}




\begin{tabular}{|c|c|c|c|c|c|c|c|c|c|c|c|c|c|}
\hline 6.60 & 200.0 & -.114 & .398 & .491 & .763 & 1.079 & 1.146 & 1.114 & 1.041 & .857 & .771 & .765 & .061 \\
\hline 6.80 & 1.0 & 1.146 & 1.708 & 1.898 & 2.279 & 2.643 & 2.934 & 3.079 & 3.204 & 3.204 & 3.000 & 2.866 & 1.620 \\
\hline 6.80 & 2.0 & 1.176 & 1.653 & 1.919 & 2.255 & 2.633 & 2.949 & 3.114 & 3.176 & 3.204 & 3.000 & 2.831 & 1.605 \\
\hline 6.80 & 3.0 & 1.301 & 1.740 & 1.944 & 2.176 & 2.623 & 2.949 & 3.041 & 3.176 & 3.204 & 2.954 & 2.812 & 1.622 \\
\hline 6.80 & 5.0 & 1.114 & 1.681 & 1.813 & 2.146 & 2.643 & 2.881 & 3.079 & 3.146 & 3.146 & 2.898 & 2.766 & 1.612 \\
\hline 6.80 & 10.0 & 1.114 & 1.519 & 1.672 & 2.079 & 2.447 & 2.763 & 2.892 & 3.000 & 3.000 & 2.771 & 2.641 & 1.444 \\
\hline 6.80 & 15.0 & .857 & 1.431 & 1.613 & 1.954 & 2.322 & 2.602 & 2.778 & 2.875 & 2.863 & 2.623 & 2.497 & 1.31 \\
\hline 6.80 & 20.0 & .820 & 1.322 & 1.505 & 1.839 & 2.204 & 2.491 & 2.591 & 2.724 & 2.732 & 2.447 & 2.360 & 1.2 \\
\hline 6.80 & 30.0 & .613 & 1.255 & 1.362 & 1.681 & 2.000 & 2.342 & 2.415 & 2.519 & 2.477 & 2.230 & 2.117 & 1.00 \\
\hline 6.80 & 50.0 & .491 & .996 & 1.176 & 1.568 & 1.826 & 2.041 & 2.204 & 2.230 & 2.146 & 1.898 & 1.822 & .80 \\
\hline 6.80 & 70.0 & .322 & .949 & 1.079 & 1.342 & 1.643 & 1.954 & 2.000 & 2.041 & 1.959 & 1.708 & 1.660 & .65 \\
\hline 6.80 & 100.0 & .230 & .740 & .863 & 1.230 & 1.477 & 1.748 & 1.813 & 1.799 & 1.672 & 1.477 & 1.449 & .52 \\
\hline 6.80 & 120.0 & .146 & .724 & .851 & 1.146 & 1.431 & 1.623 & 1.690 & 1.681 & 1.477 & 1.322 & 1.290 & .42 \\
\hline 6.80 & 150.0 & .146 & .623 & .708 & 1.000 & 1.380 & 1.531 & 1.505 & 1.462 & 1.255 & 1.146 & 1.134 & .25 \\
\hline 6.80 & 200.0 & .041 & .462 & .716 & .869 & 1.114 & 1.230 & 1.230 & 1.146 & .973 & .886 & .880 & .16 \\
\hline 7.00 & 1.0 & 1.255 & 1.845 & 2.041 & 2.342 & 2.681 & 3.041 & 3.176 & 3.255 & 3.255 & 3.041 & 2.888 & 1.71 \\
\hline 7.00 & 2.0 & 1.322 & 1.851 & 1.991 & 2.342 & 2.690 & 2.973 & 3.146 & 3.204 & 3.255 & 2.987 & 2.852 & 1.688 \\
\hline 7.00 & 3.0 & 1.279 & 1.826 & 1.978 & 2.255 & 2.699 & 2.929 & 3.146 & 3.230 & 3.204 & 2.996 & 2.862 & 1.677 \\
\hline 7.00 & 5.0 & 1.255 & 1.826 & 1.982 & 2.301 & 2.623 & 2.886 & 3.041 & 3.204 & 3.146 & 2.949 & 2.815 & 1.642 \\
\hline 7.00 & 10.0 & 1.146 & 1.672 & 1.863 & 2.146 & 2.568 & 2.826 & 2.934 & 3.079 & 3.041 & 2.785 & 2.691 & 1.52 \\
\hline 7.00 & 15.0 & .959 & 1.544 & 1.672 & 2.041 & 2.477 & 2.681 & 2.839 & 2.892 & 2.908 & 2.672 & 2.539 & 1.42 \\
\hline 7.00 & 20.0 & .973 & 1.462 & 1.591 & 1.908 & 2.362 & 2.591 & 2.690 & 2.792 & 2.756 & 2.519 & 2.382 & 1.267 \\
\hline 7.00 & 30.0 & .748 & 1.279 & 1.380 & 1.756 & 2.114 & 2.380 & 2.491 & 2.544 & 2.531 & 2.301 & 2.176 & 1.093 \\
\hline 7.00 & 50.0 & .602 & 1.114 & 1.279 & 1.580 & 1.929 & 2.146 & 2.230 & 2.322 & 2.230 & 1.978 & 1.900 & .897 \\
\hline 7.00 & 70.0 & .531 & 1.000 & 1.176 & 1.556 & 1.778 & 2.041 & 2.114 & 2.114 & 2.000 & 1.763 & 1.707 & .775 \\
\hline 7.00 & 100.0 & .447 & .924 & 1.041 & 1.301 & 1.643 & 1.869 & 1.908 & 1.869 & 1.724 & 1.519 & 1.502 & .648 \\
\hline 7.00 & 120.0 & .398 & .898 & 1.041 & 1.322 & 1.602 & 1.724 & 1.771 & 1.740 & 1.568 & 1.415 & 1.389 & .530 \\
\hline 7.00 & 150.0 & .204 & .771 & .869 & 1.176 & 1.431 & 1.568 & 1.580 & 1.531 & 1.342 & 1.204 & 1.199 & .408 \\
\hline 7.00 & 200.0 & .204 & .681 & .820 & 1.079 & 1.255 & 1.362 & 1.322 & 1.230 & 1.041 & .964 & .959 & .279 \\
\hline 7.20 & 1.0 & 1.431 & 1.903 & 2.079 & 2.380 & 2.771 & 3.041 & 3.176 & 3.255 & 3.255 & 3.041 & 2.899 & 1.748 \\
\hline 7.20 & 2.0 & 1.447 & 1.934 & 2.114 & 2.398 & 2.748 & 3.000 & 3.146 & 3.255 & 3.301 & 3.041 & 2.863 & 1.752 \\
\hline 7.20 & 3.0 & 1.447 & 1.940 & 2.114 & 2.398 & 2.708 & 3.041 & 3.176 & 3.230 & 3.230 & 3.041 & 2.867 & 1.757 \\
\hline 7.20 & 5.0 & 1.431 & 1.881 & 2.079 & 2.447 & 2.771 & 2.996 & 3.114 & 3.230 & 3.176 & 2.978 & 2.834 & 1.712 \\
\hline 7.20 & 10.0 & 1.301 & 1.756 & 1.959 & 2.255 & 2.613 & 2.875 & 3.000 & 3.041 & 3.079 & 2.826 & 2.708 & 1.611 \\
\hline 7.20 & 15.0 & 1.146 & 1.690 & 1.799 & 2.146 & 2.447 & 2.763 & 2.869 & 2.968 & 2.944 & 2.699 & 2.580 & 1.509 \\
\hline 7.20 & 20.0 & 1.146 & 1.623 & 1.820 & 2.079 & 2.415 & 2.633 & 2.756 & 2.839 & 2.771 & 2.568 & 2.430 & 1.378 \\
\hline 7.20 & 30.0 & .991 & 1.519 & 1.568 & 1.949 & 2.230 & 2.462 & 2.580 & 2.623 & 2.591 & 2.322 & 2.233 & 1.196 \\
\hline 7.20 & 50.0 & .857 & 1.279 & 1.431 & 1.623 & 2.000 & 2.204 & 2.342 & 2.362 & 2.301 & 2.041 & 1.975 & 1.000 \\
\hline 7.20 & 70.0 & .613 & 1.176 & 1.322 & 1.633 & 1.886 & 2.079 & 2.176 & 2.176 & 2.079 & 1.845 & 1.792 & .87 \\
\hline 7.20 & 100.0 & .591 & 1.079 & 1.230 & 1.505 & 1.716 & 1.929 & 1.982 & 1.959 & 1.785 & 1.613 & 1.573 & .778 \\
\hline 7.20 & 120.0 & .431 & .982 & 1.146 & 1.322 & 1.613 & 1.771 & 1.813 & 1.792 & 1.613 & 1.447 & 1.420 & .66 \\
\hline 7.20 & 150.0 & .398 & .806 & .973 & 1.301 & 1.556 & 1.663 & 1.653 & 1.568 & 1.415 & 1.279 & 1.276 & .52 \\
\hline 7.20 & 200.0 & .342 & .806 & .898 & 1.146 & 1.342 & 1.431 & 1.415 & 1.342 & 1.146 & 1.041 & 1.045 & .4 \\
\hline 7.40 & 1.0 & 1.556 & 2.079 & 2.204 & 2.519 & 2.778 & 3.041 & 3.176 & 3.301 & 3.279 & 3.079 & 2.912 & 1.81 \\
\hline 7.40 & 2.0 & 1.623 & 2.041 & 2.204 & 2.431 & 2.820 & 3.041 & 3.204 & 3.279 & 3.279 & 3.079 & 2.898 & 1.80 \\
\hline 7.40 & 3.0 & 1.580 & 2.146 & 2.255 & 2.415 & 2.806 & 3.041 & 3.204 & 3.255 & 3.255 & 3.041 & 2.894 & 1.80 \\
\hline 7.40 & 5.0 & 1.491 & 2.041 & 2.176 & 2.519 & 2.724 & 3.000 & 3.176 & 3.255 & 3.230 & 2.996 & 2.839 & 1.78 \\
\hline 7.40 & 10.0 & 1.477 & 1.919 & 2.079 & 2.322 & 2.643 & 2.914 & 3.041 & 3.114 & 3.114 & 2.875 & 2.746 & 1.71 \\
\hline 7.40 & 15.0 & 1.255 & 1.869 & 1.934 & 2.279 & 2.633 & 2.857 & 2.919 & 2.978 & 2.964 & 2.756 & 2.625 & 1.59 \\
\hline 7.40 & 20.0 & 1.230 & 1.756 & 1.845 & 2.146 & 2.477 & 2.740 & 2.813 & 2.881 & 2.863 & 2.602 & 2.498 & 1.497 \\
\hline 7.40 & 30.0 & 1.204 & 1.613 & 1.672 & 1.982 & 2.279 & 2.544 & 2.643 & 2.663 & 2.623 & 2.380 & 2.314 & 1.334 \\
\hline 7.40 & 50.0 & .924 & 1.415 & 1.505 & 1.845 & 2.079 & 2.279 & 2.398 & 2.431 & 2.322 & 2.079 & 2.021 & 1.093 \\
\hline 7.40 & 70.0 & .820 & 1.301 & 1.462 & 1.690 & 1.973 & 2.176 & 2.230 & 2.279 & 2.114 & 1.892 & 1.851 & .98 \\
\hline 7.40 & 100.0 & .740 & 1.255 & 1.380 & 1.556 & 1.756 & 1.954 & 2.000 & 2.000 & 1.851 & 1.653 & 1.631 & .8 \\
\hline 7.40 & 120.0 & .763 & 1.041 & 1.204 & 1.505 & 1.708 & 1.869 & 1.914 & 1.869 & 1.716 & 1.544 & 1.519 & .77 \\
\hline 7.40 & 150.0 & .519 & 1.079 & 1.146 & 1.362 & 1.633 & 1.732 & 1.732 & 1.663 & 1.462 & 1.342 & 1.342 & .66 \\
\hline 7.40 & 200.0 & .462 & .875 & 1.041 & 1.204 & 1.447 & 1.519 & 1.491 & 1.362 & 1.204 & 1.146 & 1.130 & .5 \\
\hline 7.60 & 1.0 & 1.681 & 2.146 & 2.204 & 2.505 & 2.799 & 3.041 & 3.255 & 3.322 & 3.301 & 3.079 & 2.922 & 1.860 \\
\hline 7.60 & 2.0 & 1.602 & 2.079 & 2.301 & 2.505 & 2.799 & 3.146 & 3.204 & 3.301 & 3.301 & 3.041 & 2.918 & 1.84 \\
\hline 7.60 & 3.0 & 1.672 & 2.114 & 2.255 & 2.505 & 2.845 & 3.079 & 3.204 & 3.279 & 3.255 & 3.079 & 2.901 & 1.81 \\
\hline 7.60 & 5.0 & 1.613 & 2.000 & 2.230 & 2.462 & 2.785 & 3.079 & 3.176 & 3.255 & 3.230 & 3.000 & 2.877 & 1.790 \\
\hline 7.60 & 10.0 & 1.544 & 2.114 & 2.230 & 2.447 & 2.690 & 2.959 & 3.114 & 3.204 & 3.146 & 2.903 & 2.786 & 1.748 \\
\hline 7.60 & 15.0 & 1.462 & 1.881 & 2.079 & 2.301 & 2.643 & 2.863 & 2.982 & 3.041 & 3.000 & 2.778 & 2.654 & 1.627 \\
\hline 7.60 & 20.0 & 1.342 & 1.934 & 2.041 & 2.204 & 2.505 & 2.732 & 2.881 & 2.940 & 2.898 & 2.643 & 2.521 & 1.50 \\
\hline 7.60 & 30.0 & 1.342 & 1.771 & 1.851 & 2.079 & 2.362 & 2.591 & 2.672 & 2.732 & 2.681 & 2.431 & 2.330 & 1.41 \\
\hline 7.60 & 50.0 & 1.041 & 1.544 & 1.663 & 1.863 & 2.176 & 2.415 & 2.477 & 2.491 & 2.398 & 2.146 & 2.086 & 1.20 \\
\hline 7.60 & 70.0 & .982 & 1.398 & 1.556 & 1.771 & 2.000 & 2.204 & 2.230 & 2.301 & 2.204 & 1.964 & 1.921 & 1.07 \\
\hline
\end{tabular}




\begin{tabular}{|c|c|c|c|c|c|c|c|c|c|c|c|c|c|}
\hline 7.60 & 100.0 & .881 & 1.301 & 1.477 & 1.633 & 1.898 & 2.079 & 2.079 & 2.079 & 1.886 & 1.724 & 1.702 & .923 \\
\hline 7.60 & 120.0 & .839 & 1.204 & 1.398 & 1.613 & 1.833 & 1.954 & 1.973 & 1.934 & 1.771 & 1.613 & 1.600 & .904 \\
\hline 7.60 & 150.0 & .732 & 1.204 & 1.230 & 1.477 & 1.699 & 1.785 & 1.792 & 1.756 & 1.544 & 1.431 & 1.422 & .805 \\
\hline 7.60 & 200.0 & .663 & 1.079 & 1.176 & 1.342 & 1.491 & 1.568 & 1.544 & 1.431 & 1.255 & 1.204 & 1.196 & .607 \\
\hline 7.80 & 1.0 & 1.857 & 2.301 & 2.431 & 2.531 & 2.875 & 3.114 & 3.255 & 3.301 & 3.342 & 3.114 & 2.938 & 1.961 \\
\hline 7.80 & 2.0 & 1.771 & 2.301 & 2.362 & 2.613 & 2.914 & 3.079 & 3.255 & 3.322 & 3.301 & 3.114 & 2.936 & 1.924 \\
\hline 7.80 & 3.0 & 1.716 & 2.230 & 2.342 & 2.591 & 2.914 & 3.146 & 3.230 & 3.279 & 3.301 & 3.079 & 2.939 & 1.899 \\
\hline 7.80 & 5.0 & 1.763 & 2.204 & 2.342 & 2.531 & 2.833 & 3.114 & 3.230 & 3.255 & 3.301 & 3.041 & 2.901 & 1.906 \\
\hline 7.80 & 10.0 & 1.663 & 2.176 & 2.279 & 2.477 & 2.771 & 2.982 & 3.114 & 3.204 & 3.146 & 2.934 & 2.807 & 1.813 \\
\hline 7.80 & 15.0 & 1.613 & 2.000 & 2.176 & 2.398 & 2.690 & 2.892 & 2.987 & 3.079 & 3.041 & 2.806 & 2.669 & 1.734 \\
\hline 7.80 & 20.0 & 1.556 & 1.968 & 2.041 & 2.301 & 2.544 & 2.778 & 2.908 & 2.968 & 2.934 & 2.681 & 2.573 & 1.631 \\
\hline 7.80 & 30.0 & 1.342 & 1.839 & 1.959 & 2.176 & 2.431 & 2.643 & 2.716 & 2.763 & 2.732 & 2.477 & 2.364 & 1.487 \\
\hline 7.80 & 50.0 & 1.204 & 1.681 & 1.820 & 1.944 & 2.204 & 2.398 & 2.519 & 2.544 & 2.431 & 2.204 & 2.127 & 1.307 \\
\hline 7.80 & 70.0 & 1.114 & 1.591 & 1.672 & 1.875 & 2.079 & 2.279 & 2.342 & 2.362 & 2.230 & 2.000 & 1.964 & 1.193 \\
\hline 7.80 & 100.0 & .964 & 1.447 & 1.556 & 1.672 & 2.000 & 2.114 & 2.176 & 2.146 & 1.978 & 1.799 & 1.763 & 1.045 \\
\hline 7.80 & 120.0 & .968 & 1.362 & 1.505 & 1.672 & 1.833 & 2.041 & 2.041 & 1.978 & 1.806 & 1.653 & 1.626 & .947 \\
\hline 7.80 & 150.0 & .869 & 1.342 & 1.380 & 1.568 & 1.732 & 1.881 & 1.857 & 1.778 & 1.613 & 1.491 & 1.490 & .877 \\
\hline 7.80 & 200.0 & .778 & 1.114 & 1.255 & 1.447 & 1.568 & 1.633 & 1.591 & 1.505 & 1.322 & 1.230 & 1.236 & .765 \\
\hline 8.00 & 1.0 & 1.875 & 2.322 & 2.462 & 2.633 & 2.886 & 3.146 & 3.279 & 3.362 & 3.342 & 3.146 & 2.974 & 1.981 \\
\hline 8.00 & 2.0 & 1.919 & 2.255 & 2.415 & 2.613 & 2.929 & 3.146 & 3.255 & 3.342 & 3.322 & 3.114 & 2.961 & 1.988 \\
\hline 8.00 & 3.0 & 1.881 & 2.255 & 2.380 & 2.613 & 2.863 & 3.146 & 3.279 & 3.322 & 3.322 & 3.079 & 2.935 & 1.955 \\
\hline 8.00 & 5.0 & 1.839 & 2.279 & 2.380 & 2.591 & 2.908 & 3.114 & 3.204 & 3.301 & 3.301 & 3.079 & 2.904 & 1.939 \\
\hline 8.00 & 10.0 & 1.806 & 2.279 & 2.398 & 2.491 & 2.813 & 3.041 & 3.146 & 3.230 & 3.204 & 2.959 & 2.832 & 1.850 \\
\hline 8.00 & 15.0 & 1.708 & 2.114 & 2.255 & 2.431 & 2.724 & 2.949 & 3.000 & 3.114 & 3.079 & 2.833 & 2.725 & 1.799 \\
\hline 8.00 & 20.0 & 1.613 & 2.079 & 2.176 & 2.415 & 2.633 & 2.839 & 2.954 & 3.041 & 2.949 & 2.724 & 2.621 & 1.702 \\
\hline 8.00 & 30.0 & 1.477 & 1.940 & 2.041 & 2.255 & 2.519 & 2.681 & 2.799 & 2.839 & 2.763 & 2.544 & 2.450 & 1.508 \\
\hline 8.00 & 50.0 & 1.301 & 1.732 & 1.857 & 2.041 & 2.279 & 2.477 & 2.580 & 2.591 & 2.505 & 2.230 & 2.201 & 1.362 \\
\hline 8.00 & 70.0 & 1.301 & 1.568 & 1.740 & 1.964 & 2.176 & 2.342 & 2.398 & 2.431 & 2.279 & 2.079 & 2.033 & 1.279 \\
\hline 8.00 & 100.0 & 1.176 & 1.591 & 1.653 & 1.806 & 1.996 & 2.146 & 2.204 & 2.204 & 2.041 & 1.833 & 1.809 & 1.167 \\
\hline 8.00 & 120.0 & 1.114 & 1.462 & 1.568 & 1.724 & 1.944 & 2.041 & 2.079 & 2.079 & 1.869 & 1.716 & 1.695 & 1.090 \\
\hline 8.00 & 150.0 & 1.079 & 1.415 & 1.519 & 1.643 & 1.806 & 1.914 & 1.934 & 1.869 & 1.681 & 1.556 & 1.550 & 1.049 \\
\hline 8.00 & 200.0 & .929 & 1.255 & 1.398 & 1.505 & 1.653 & 1.732 & 1.672 & 1.568 & 1.415 & 1.342 & 1.340 & .874 \\
\hline
\end{tabular}

For soil sites, an amplitude-dependent amplification factor is calculated, using the empirical factors of Abrahamson and Silva (1997). The soil amplification factor is given by: $\ln$ factor $=a_{10}+a_{11}\left(\mathrm{pga}_{\text {rock }}+c_{5}\right)$, where $\mathrm{pga}_{\text {rock }}$ is the expected rock amplitude in units of $g, c_{5}=0.03$ and the remaining constants are as follows (for intermediate frequencies, linear interpolation of coefficients may be used).

$\begin{array}{cccccccrrrr}\begin{array}{c}\text { Frequency } \\ (\mathrm{Hz})\end{array} & .14 & .20 & .28 & .56 & .79 & 1.12 & 2.24 & 4.47 & 8.91 & 12.59 \\ a_{10} & .664 & .664 & .640 & .610 & .512 & .370 & .020 & -.398 & -.595 & -.609 \\ a_{11} & .040 & .040 & .040 & .040 & .020 & -.028 & -.136 & -.234 & -.280 & -.280\end{array}$

